\title{
LA APLICACIÓN DE LA LEY DEL TRABAJO DE MUJERES Y NIÑOS DE 1900 EN LAS MEMORIAS DE LA INSPECCIÓN DE TRABAJO (I)
}

\author{
Daniel Vallès Muñío \\ Profesor asociado en el Departamento de Historia del Derecho y de las Instituciones \\ Universitat Autònoma de Barcelona
}

\begin{abstract}
En esta primera parte del trabajo analizamos la Ley del trabajo de mujeres y niños de 1900 y su tramitación parlamentaria. A partir de la creación de la inspección de trabajo de 1906, analizamos el relato que la inspección llevó a sus Memorias anuales sobre el cumplimiento de la ley de 1900. Con ello queremos exponer si dicha norma se cumplió o no y, sobre todo, de qué manera lo expresan los miembros de la inspección de trabajo. En esta primera entrega únicamente examinamos las Memorias de 1907 y 1908, dejando las siguientes y el examen de los datos estadísticos para futuras entregas.

In this first part of the paper we analyze the Women and Children's Labor Act of 1900 and its parliamentary procedure. We also analyze the historical account of the Spanish labor inspection, created on 1906, that is explained in its Annual Reports on the fulfillment of the Women and Children's Labor Act of 1900. Analyzing its historical account, we want to expose if this norm was fulfilled or not and, above all, how the members of the labor inspection expressed that lack of fulfillment. In this first part of the paper, we only examined the 1907 and 1908 Reports. The rest of the Reports and its statistical data will be analyzed in the next parts of the paper.
\end{abstract}

Title: The application of the Women and Children Work Act of 1900 according to the reports of the Spanish work inspection.

Palabras clave: ley de mujeres y niños, inspección de trabajo, memorias, historia social Key words: women and children work Act, work inspection, reports, social history

IUSLabor 3/2018, ISSN 1699-2938, pp. 301-350

DOI. 10.31009/IUSLabor.2018.i03.13

\section{Sumario}

1. Objetivo

2. La primera normativa protectora de las mujeres y los niños en el estado español 2.1. La Ley de Mujeres y Niños de 1900 y su tramitación 
3. Las Memorias de la inspección y la aplicación de la ley de mujeres y niños 3.1. Memoria de 1907

3.2. Memoria de 1908

4. Anexo: comparativa de los textos de la Ley de mujeres y niños de 1900 durante su tramitación parlamentaria

5. Bibliografía 


\section{Objetivo}

El motivo de este trabajo es averiguar si se cumplía la primera legislación española sobre la protección laboral de las mujeres y los niños a partir de 1900. Para ello utilizaremos como fuente los documentos de la Inspección de Trabajo española creada en 1906, sobre todo sus Memorias.

Partimos de la presunción que esta normativa no se cumplía voluntariamente por los patronos y nos planteamos como hipótesis si ese incumplimiento también podría venir amparado por la actitud de las propias mujeres y de las madres y padres de los niños. Así, nos preguntamos si la imperiosa subsistencia incentivó al incumplimiento voluntario de la norma por parte de los beneficiados por la protección que establecía la misma. En caso afirmativo, queremos exponer si la inspección de trabajo española también comprobó que fue esa necesidad imperiosa una de las causas de dicho incumplimiento.

Además, también nos preguntamos si la ratio de esas normas protectoras era, de hecho, un obstáculo a la competencia salarial que mujeres y niños planteaban a los trabajadores varones adultos. Con ello, lejos de tener un motivo esencialmente protector, cabe cuestionarse tanto los motivos como los efectos de esa legislación protectora en el mercado laboral español hasta el inicio de la Primera Guerra Mundial.

También nos interesa mostrar el lenguaje, el relato y los motivos que la propia inspección de trabajo daba para el cumplimiento o el incumplimiento de la norma. Cómo explicaba la aplicación de la ley también nos ayudará a capturar el significado que la misma tenía para los propios integrantes de la inspección, así como los destinatarios de la norma.

La manera como relataba los casos de incumplimiento el que escribió las Memorias de la inspección nos da mucha información acerca de la situación de las trabajadoras, de los menores empleados, de la situación de las industrias y su dependencia de estos trabajadores precarios para ser competitivas, etc. De hecho, este relato sería un espejo sustentado por un funcionario estatal (el que escribe las Memorias o el propio inspector regional) que muestra una parte de la realidad subalterna de las trabajadoras españolas durante los años previos a la Primera Guerra Mundial.

Asumimos, y así lo prueban las palabras de las Memorias, que el espejo es más o menos cóncavo, ya que parte de una premisa asumida por el escritor de las Memorias: la ley de mujeres y niños de 1900 era una buena norma. La inspección, como veremos, no se 
cuestiona la corrección de la norma, es decir, si estaba bien construida para conseguir sus objetivos.

Por este motivo hemos creído interesante presentar una breve introducción sobre el articulado de la ley de mujeres y niños de 1900 y su curioso camino legislativo. Para ello incorporamos un anexo que compara los dos dictámenes que tuvo el proyecto de ley con el texto definitivamente promulgado. Con ello comprobaremos que el proyecto de ley presentado por Eduardo Dato no se corresponde totalmente con el articulado de la ley efectivamente aprobada.

También es necesario tener en cuenta que el reflejo de este espejo es esencialmente parcial. Y ello vendría motivado por una de las características del inicio del servicio de inspección de trabajo: la precariedad de sus medios. Desde el principio, la institución estuvo faltada de recursos, sobre todo personales, es decir, faltaban inspectores para controlar una masa crítica de industrias, fábricas, patronos y trabajadores que debían inspeccionar. Por ello, por la falta de inspectores que pudiera dar la correspondiente información para construir las Memorias, éstas no pueden evitar ser parciales y mostrar una pequeña realidad de la situación laboral de aquellos años.

Asumimos esta limitación del objeto mostrado por una fuente parcial en esencia y por ello nos resulta muy difícil extraer conclusiones lo suficientemente generales para poder realizar afirmaciones del tipo "la ley de mujeres y niños de 1900 no se cumplió". Intentaremos evitarlo, ya que afirmaciones como esta serían fácilmente refutables con estudios locales o regionales detallados, en caso de tener los datos y las fuentes adecuados.

Pero ello no obsta para que el propio relato de la inspección permita extraer pequeñas historias de la clase obrera que ayude a saber si la ley estudiada se cumplía y de qué manera. Además, la exposición de dicho relato se realiza de manera cronológica, a partir de las Memorias anuales de la Inspección, y de manera geográfica, teniendo en cuenta las regiones del estado español en que se dividió la práctica de la propia institución.

Ello nos permitirá presentar una comparativa sobre el cumplimiento de la norma de temporal y espacial: ¿se incumplió en los primeros años y más adelante sí se cumplió? ¿Por qué? ¿Tuvo que ver más el incremento de personal de la inspección o una disminución de la natalidad ${ }^{1}$ y, por tanto, de la necesidad del salario del menor? ¿En las zonas agrícolas latifundistas del sur del estado se llegó a cumplir la norma? ¿Por qué los

\footnotetext{
1 CAMPS, E.; Trabajo infantil y estrategias familiares durante los primeros estadios de la industrialización catalana (1850-1925). Esbozos a partir del estudio de un caso; Cuadernos de Historia Contemporánea; volumen 24, 2002, pp. 263-279.
} 


\section{IUSLabor 3/2018}

industriales y los propios obreros del tejido de Catalunya incumplía voluntariamente la ley? ¿O más bien era necesidad ${ }^{2}$ y la subsistencia de las clases obreras empobrecidas lo que forzaba a que sus hijos trabajaran? ¿Qué decía la inspección al respecto?

Para contestar a estas respuestas también utilizaremos los datos estadísticos que nos aportan las propias Memorias. Es decir, no nos quedaremos con el relato del que escribe la Memoria, sino que incorporaremos los datos de las tablas estadísticas. Por ejemplo, ¿por qué no se impuso ninguna sanción durante los primeros años en una determinada región, si se afirma que la ley no se cumplía? ¿Qué evolución tuvieron las infracciones? ¿Qué tipo de industrias se inspeccionaron repetidamente y en qué zonas?

Con estas tablas también podremos obtener otros datos que nos ayuden a exponer algunas conclusiones parciales, sin olvidar que estos datos (igual que el propio relato) también pecan de parcialidad. Por ejemplo, ¿existió algún incremento salarial en los trabajadores adultos por el hecho de que los menores fueron expulsados del mercado laboral? Si existió dicho incremento, ¿llegó a ser suficiente para que los trabajadores adultos no tuvieran la necesidad de volver a emplear a sus hijos? ¿Y fue suficiente comparándolo con el incremento de precios de los bienes? Así, con la utilización de estos datos podremos dar alguna explicación más completa o, como mínimo, con algún argumento que la soporte y le dé solidez.

Con todo ello queremos mezclar una aproximación tanto cuantitativa como del relato a la aplicación y al cumplimiento de la ley de mujeres y niños de 1900 durante los primeros catorce años de la norma.

Nuestra descripción acaba en el 1914, cuando se inicia la Primera Guerra Mundial y la neutralidad del estado español provoca un aumento de la producción industrial ${ }^{3}$, de la inflación, el encarecimiento de la vida y un empeoramiento de las condiciones salariales reales ${ }^{4}$, lo que creemos desdibujaría el objeto de nuestro trabajo y, de hecho, lo haría

\footnotetext{
${ }^{2}$ ESPUNY TOMÁs, M.J.; Una tarea preventiva y represiva: las primeras actuaciones; en ESPUNY TOMÁS, M.J.; PAZ Torres, O. (coordinadoras); Inspección de Trabajo. 1906-2006; Tirant lo Blanc, Valencia, 2008, p. 53.

${ }^{3}$ Por ejemplo, véase el caso de la industria lanera de Sabadell, en DEU I BAIGUAL, E.; Els beneficis industrials durant la Primera Guerra Mundial: el cas de la industria llanera de Sabadell; Recerques: historia, economía, cultura; $\mathrm{n}^{\circ}$ 20, 1988. O el caso de la provincia de A Coruña en MIRÁs, J.A.; El impacto de la Primera Guerra Mundial en la industria de A Coruña; Revista de Historia Industrial; $\mathrm{n}^{\circ} 29$, año XIV, 2005, 3, págs. 143-162. También sobre Catalunya, CALVo, À.; Estructura industrial i sistema productiu a Catalunya durant la Primera Guerra Mundial; Recerques: historia, economía, cultura; n 20, 1988.

${ }^{4}$ En GABRIEL, P.; Sous $i$ cost de la vida a Catalunya a l'entorn dels anys de la Primera Guerra Mundial; Recerques: historia, economía, cultura; no 20, 1988, págs. 79 y ss. se explica de manera muy interesante la evolución a la baja de los salarios reales durante esos años, es decir, los salarios nominales disminuidos
} 
mucho más complejo. Por ello, posponemos para el futuro el análisis del impacto de la Primera Guerra Mundial en la clase obrera española, según la Inspección de Trabajo 5 .

\section{La primera normativa protectora de las mujeres y los niños en el estado español}

Como es sabido, la primera norma efectivamente promulgada ${ }^{6}$ que protegía los derechos de mujeres y niños fue la llamada Ley Benot, de 24 de julio de $1873^{7}$, pero su incumplimiento fue genérico. Así lo atestiguan las respuestas que se hicieron a las preguntas de la Comisión de Reformas Sociales, que prueban que los jurados mixtos mencionados en la ley como principales encargados de la inspección de la norma no se llegaron a constituir ${ }^{8}$.

Pero a los efectos de este trabajo nos interesan únicamente la llamada Ley de Mujeres y Niños de 1900, en tanto que primera norma protectora del trabajo femenino e infantil, con visos de ser cumplida.

\subsection{La Ley de Mujeres y Niños de 1900 y su tramitación.}

a) Esta norma es de 13 de marzo de 1900 y apareció en la Gaceta $n^{\circ} 73$ de 14 de marzo. Su contenido puede resumirse en los siguientes aspectos:

- Limitación de la edad para empezar a trabajar por cuenta ajena:

por los incrementos de precios y la inflación. Además, también se explica que existió una cierta redistribución de la renta nacional favorable a los trabajadores de las zonas más industrializadas y negativo para los trabajadores agrícolas.

${ }^{5}$ De hecho, la propia inspección de trabajo hizo un extenso trabajo sobre el impacto de la Gran Guerra sobre la industria española. Véanse, Instituto de Reformas Sociales; Informes de los Inspectores del Trabajo sobre la influencia de la guerra europea en las industrias españolas durante el año 1915; Imprenta de la sucesora de M. Minuesa de los Ríos, Madrid, 1916. Los tres volúmenes de Instituto de Reformas Sociales; Informes de los Inspectores del Trabajo sobre la influencia de la guerra europea en las industrias españolas (1917-1918); Sobrinos de la sucesora de M. Minuesa de los Ríos; Madrid, 1918 y 1919. Y Instituto de Reformas Sociales; Resumen de las informaciones de los inspectores del trabajo acerca de las consecuencias sufridas por las industrias en España con motivo del actual estado de guerra; Imprenta de la sucesora de M. Minuesa de los Ríos, Madrid, 1914.

${ }^{6}$ Obviamos, por ejemplo, el proyecto de ley del Ministro de Fomento Sr. Manuel Alonso Martínez, sobre ejercicio, policía, sociedades, jurisdicción e inspección de la industria manufacturera, consultable en la Gaceta $\mathrm{n}^{\circ} 1010$, de 10 de octubre de 1855, que no se aprobó. Sobre otros proyectos no aprobados, véase MONTERO GARCíA, F.; La polémica sobre el intervencionismo y la primera legislación obrera en España. 1890-1900. $2^{a}$ parte: el debate político-parlamentario; Revista de Trabajo, nº61-62, 1981, pp. 42 a 48.

${ }^{7}$ Gaceta $n^{\circ} 209$, de 28 de julio.

${ }^{8}$ Espuny ToMÁs, M.J.; Los orígenes de la Inspección de Trabajo en España (1906-2006); IusLabor 1/2006, p. 2. También en RAmos VÁZQUEZ, I.; Derecho internacional obrero. Origen y concepto; IusLabor 3/2017, p. 344. 
i. Para ambos sexos, prohibición total del trabajo para menores de 10 años (artículo 1). Cabe tener en cuenta que, según apunta BORRÁs ${ }^{9}$ para la industria catalana, la existencia del trabajo infantil menor de 10 años era relativamente poca, por lo que podríamos cuestionar el impacto real de esta prohibición.

ii. Para ambos sexos, prohibición de trabajar para menores de entre 10 y 14 años más de 6 horas en establecimientos industriales y más de 8 horas en el comercio.

iii. Al cabo de dos años, tal y como estableció la ley, se promulgó el Real Decreto de 26 de junio de $1902^{10}$ que determina que "no podrá exceder de 11 horas la jornada de trabajo para las personas que son objeto" de la Ley de Mujeres y Niños.

iv. Para ambos sexos, prohibición total del trabajo nocturno ${ }^{11}$ para menores de 14 años (artículo 4) y en las industrias que determinen las Juntas Locales y Provinciales de Reforma Social para los menores de 14 a 18 años, así como que el trabajo nocturno no podrá exceder de 48 horas semanales.

v. Prohibición para los menores de 16 años (artículo 5) de los trabajos subterráneos, en los que se manipulen substancias inflamables, o en industrias calificadas de peligrosas o insalubres ${ }^{12}$, y en limpieza de motores "mientras esté funcionando la maquinaria”.

vi. Prohibición para los niños menores de 16 años y para las mujeres menores de edad en talleres de imprenta en los que "puedan herir su moralidad" (artículo $6.1)^{13}$.

\footnotetext{
${ }^{9}$ Para BorRás LloP, J.M.; El trabajo infantil en la industria de Barcelona según el Censo Obrero de 1905; Historia Social, $\mathrm{n}^{\mathrm{o}} 33,1999$, p. 28, el trabajo de menores de 10 años en la industria barcelonesa debía de ser escaso. Por ello, podríamos cuestionar el impacto que esta prohibición podría haber tenido. Pero pone en cuestión esa afirmación cuando utiliza las cifras de escolarización infantil entre 6 y 12 años matriculados en las escuelas públicas barcelonesas y se da cuenta que, en 1908, es una de las más bajas del estado español, lo que da a entender que sí existía una gran masa de oferta obrera infantil.

${ }^{10}$ Gaceta $\mathrm{n}^{\mathrm{o}} 178$, de 27 de junio de 1902.

${ }^{11}$ Según esa norma, debía entenderse como trabajo nocturno 'el que tenga lugar desde las 7 de la tarde hasta las 5 de la mañana, con descansos, como mínimo, de 1 hora y media'.

${ }^{12}$ El Real Decreto de 25 de enero de 1908 estableció la lista de industrias vetadas, Gaceta no 27 de 27 de enero de 1908. Irá apareciendo a lo largo de este trabajo en diferentes ocasiones, puesto que muchos incumplimientos estarán relacionados con la lista de industrias que contiene.

${ }^{13}$ BORRÁs LlOP, op. cit. p. 37, nota que, después del sector textil, en la industria del papel y de las artes gráficas es donde se utiliza más trabajo infantil. Además, explica que el trabajo infantil femenino se daba más en el sector del papel, sobre todo en el de las cajas y juguetes de cartón; 'es en estas empresas donde se daba una ocupación más intensa de mano de obra infantil, de todas las detalladas por el Censo', casi el doble número de niñas y niños que de adultos. Según BORRÁs LLOP, debido a esta gran demanda de trabajo infantil la Asociación de fabricantes de cajas de cartón de Barcelona reclamó a las autoridades en 1907 'que se les eximiera de la aplicación de la ley de 1900, permitiéndoles la contratación a tiempo completo de niños con edades comprendidas entre los doce y catorce años'; de manera similar actuaron los fabricantes de vidrio de Barcelona en 1905 con un resultado oficialmente negativo por la oposición del Instituto de Reformas Sociales, aunque seguía incumpliendo la norma. En la página 39 nota las
} 
vii. Prohibición para ambos sexos menores de 16 años para trabajos de "agilidad, equilibrio, fuerza o dislocación en espectáculos públicos" ${ }^{\prime 14}$.

- Prohibición del trabajo en domingo y en días festivos (artículo 6 in fine).

- Obligatoriedad de 2 horas diarias "por lo menos, no computables entre las del trabajo" para formación primaria y religiosa para menores de 14 años que no la hubiesen recibido.

- Artículo 8 in fine: "los niños que acrediten saber leer y escribir se les admitirá en la fábrica 1 año antes del a edad marcada" en la ley.

- Prohibición de trabajo durante las 3 semanas posteriores al alumbramiento (artículo 9.1) con reserva del puesto de trabajo, pero no consta el derecho de la mujer a seguir siendo retribuida durante este periodo.

- Permiso de lactancia durante 1 horas al día de carácter divisible y no descontable a efectos de cobro de jornales.

- Obligación de vacunación por parte de niños, jóvenes y mujeres (artículo 10).

- Separación entre sexos en los alojamientos de los obreros que dependan de los patronos (artículo 11).

- Finalmente, la inspección será la competente para inspeccionar el cumplimiento de la ley y a falta de ésta lo serán las Juntas Locales y Provinciales de Reformas Sociales (artículo 14).

- Las asociaciones de patronos o de obreros de una industria y de una localidad concreta podían solicitar al gobierno la suspensión de la aplicación de las normas, "exponiendo los daños o inconvenientes prácticos" que se originasen, previa audiencia de la Junta Local de Reformas Sociales o la Comisión de Reformas Sociales (artículo 15) ${ }^{15}$.

b) Si este es el contenido resumido de la ley, examinemos cuál fue el origen del mismo, es decir, cuál fue su tramitación parlamentaria y qué sentido le dieron los legisladores a la letra de la norma.

huelgas que existieron en el sector de los tipógrafos y encuadernadores por el uso de trabajo infantil menor de 14 años, dado que suponía una competencia para el obrero adulto varón.

${ }^{14} \mathrm{El}$ redactado del apartado 6.2 de la norma es casi idéntico al del artículo 1.1 de la Ley de 27 de julio de 1878 que prohibía los trabajos peligrosos de los niños, aparecida en la Gaceta n 209 de 28 de julio de 1878. Podríamos argumentar que el hecho que en 1900 vuelva a aparecer una prohibición de una ley de 1878 es porque ésta no se cumplía.

${ }^{15}$ BORRÁs LLOP, J.M.; Actitudes patronales ante la regularización del trabajo infantil, en el tránsito del siglo XIX al XX. Salarios de subsistencia y economías domésticas; Hispania: revista española de historia; volumen $55, n^{\circ} 190,1995$, p. 637-638, explica como una vez aprobada la norma, comenzaron a llegar solicitudes de suspensión de su aplicación; por ejemplo, la de los fabricantes de vidrio de la provincia de Barcelona en 1905 o la de los industriales de la hilatura de lana y de fabricación de mantas de Bocairent (Valencia), que también aparece en las memorias que comentamos. 
El proyecto de ley remitido por el Senado de fecha 18 de diciembre de $1899^{16}$ tiene diferentes interesantes respecto a la ley finalmente aprobada ${ }^{17}$ :

- En el proyecto se aceptaba el trabajo de menores de 10 años que trate de "el aseo, la conservación y el cuidado de los locales donde se ejerza la industria y el comercio" mientras que en la ley aprobada se prohíbe cualquier tipo de trabajo para menores de esta edad (artículo 1 del proyecto).

En la discusión de este artículo, Gumersindo de Azcárate ${ }^{18}$, entre otros diputados, ya observó que permitir el trabajo de los menores de 10 años en ese tipo de trabajos era "un medio de hacer que quede sin efecto la prohibición, porque el patrono que lo tenga a bien, encontrará siempre el medio de demostrar que se trata de trabajos auxiliares, de aseo, etc. La cuestión está en que entren o no entren en la fábrica".

- En el proyecto se propone una limitación más en su artículo 2 que la del trabajo de menores de 10 a 14 años: así, para el trabajo de los menores de entre los 14 y los 16 años, que podrán trabajar durante 8 horas "en los establecimientos industriales y 10 en los mercantiles" con descansos de hora y media como mínimo (artículo 2.2 del proyecto). En cambio, en el artículo 2 de ley sólo consta la limitación del trabajo para los menores de 10 a 14 años. Durante la tramitación parlamentarias desapareció esta limitación de 14 a 16 años.

- En el proyecto no consta la referencia al trabajo en horas extraordinarias (artículo 3 de la ley) para suplir la pérdida de horas en casos de averías, sequías o riadas, o en casos de paros forzosos en industrias a vapor o cuyos productos tenga la venta limitada "a cortas temporadas estacionales". Es decir, durante la tramitación se incorporó esta previsión de incremento de las horas de trabajo.

- Mientras en el proyecto la prohibición de trabajo nocturno para los menores de 14 años es total (artículo 3 del proyecto), en la ley (artículo 4 de la ley) se incorpora una prohibición relativa, es decir, aquella susceptible de ser establecida por las Juntas Locales y Provinciales de Reforma Social en determinadas industrias para menores de 14 a 18 años. En este punto la tramitación fue más protectora del menor, al menos en teoría.

\footnotetext{
${ }^{16}$ Apéndice $5^{\circ}$ del Diario de Sesiones de Cortes n ${ }^{\circ} 90$ de 19 de diciembre de 1899.

${ }^{17} \mathrm{Al}$ respecto, al final de este trabajo se acompaña una comparativa del articulado del proyecto, de los dictámenes y de la ley efectivamente aprobada, en la que está coloreados las diferencias entre unos y otros.

${ }^{18}$ Diario de Sesiones no 131 de 16 de febrero de 1900, p. 4525.
} 
- En el proyecto no se contempló la prohibición que sí existe en la ley (artículo 5.3 de ésta) relativa a que los menores de 16 no podrían trabajar en "la limpieza de motores y piezas de transmisión, mientras esté funcionando la maquinaria". En este punto la ley promulgada también fue más protectora de la salud de los menores.

- En el proyecto tampoco está la limitación laboral, que sí se encuentra en la ley (artículo 6.1 de ésta) sobre la prohibición de que niños menores de 16 años y mujeres menores de edad pudieran trabajar en empresas de impresión que "sean de tal naturaleza que puedan herir su moralidad". En cambio, sí existe en ambos textos la referencia a la prohibición de trabajos peligrosos del circo, pero el proyecto yerra la remisión normativa y se remite a la Ley Benot de 1 de julio de 1873, que, como es sabido, no regula los trabajos de equilibrio, fuerza o dislocación de los menores. La ley sí remite, acertadamente, a la Ley de 26 de julio de $1878^{19}$.

- Resulta muy curioso que en el proyecto de 18 de diciembre de 1899 no aparecen en ningún momento las Juntas Locales y Provinciales de Reformas Sociales, pero, como hemos visto, sí lo hacen en la ley (artículo 7) y además con facultades inspectoras y de establecimientos de excepciones a la norma. Es decir, en 1899 no se tuvo en cuenta crear este organismo paritario, en el sentido de estar formado en igual número de patronos y obreros, cuya inspiración marcará la gran mayoría de regulación laboral posterior ${ }^{20}$.

\footnotetext{
${ }^{19}$ Para ESPUNY TOMÁs, M.J.; Mendicidad infantil: la ley sobre mendicidad y vagancia de los menores de diez y seis años de 23 de julio de 1903; IusLabor 4/2005, p. 4, es interesante remarcar que la Ley de 1900 remite únicamente a la prohibición de trabajos peligrosos de 1878 , pero olvida voluntariamente la cualquier referencia a la mendicidad (también recogida en la ley de 1878), porque ya se 'estaba gestando' un proyecto de ley 'que daría lugar a unas disposiciones sobre la protección a la infancia y represión de la mendicidad que se desarrollarán entre 1903 y 1920', como fue la Ley sobre mendicidad y vagancia de los menores de 16 años de 23 de julio de 1903.

${ }^{20}$ Véase la discusión sobre el artículo 7 de la ley en el Diario de Sesiones no 139 de 1 de marzo de 1900 , págs. 4835 y ss. Para el diputado Miguel Morayta Sagrario toda la ley 'depende de lo que hayan de ser la Junta Locales y Provinciales de que habla el artículo $7^{\circ}$. Y añade de forma crítica (p. 4837) que la Junta ' ha de ser todo en todo favorable a los patronos [...] porque el elemento civil como el eclesiástico representan intereses conservadores, intereses permanentes, el interés del capital; por consiguiente, resulta que se da un número mayor de votos a un elemento que a otro, en una Junta que lo ha de ser todo, que lo ha de representar todo, que ha de disponerlo todo'. En opinión del Ministro de la Gobernación, el Sr. Eduardo Dato, la configuración de la Junta ofrecía 'garantías de absoluta imparcialidad a obreros y a patronos'. Sobre las Juntas Locales y Provinciales de Reformas Sociales, véase, por ejemplo, a BORRÁS LLOP, J.M.; Los límites del primer intervencionismo estatal en el mercado laboral: las Juntas de Reformas Sociales, las Delegaciones del Consejo de Trabajo y el empleo de mujeres y niños (Cataluña, 1900-1930); en BORDERÍAS, C. (editora); Género y políticas del trabajo en la España contemporánea. 1836-1936; Història del Treball, n 2, Icaria Editorial, Barcelona, 2007, pp. 61 a 96.
} 
- En el proyecto (artículo 6 de éste) sí se contempla la limitación del horario laboral en un máximo de 10 horas para las mujeres mayores de 16 años, con descansos de 2 horas; en cambio, en la ley desapareció esta limitación. En este punto, la ley empeoró el proyecto.

- En el proyecto (artículos 7 y 8 de éste) aparece la posibilidad de que el Gobierno autorizase el trabajo nocturno de los menores entre 16 y 23 años en industrias que exijan la continuidad de la producción, en productos de primera necesidad "cuya expedición deba verificarse por la mañana" (pe. el pan) o en trabajos de urgencia cuya omisión pudiese suponer perjuicios irreparables. En la ley, la posibilidad de permitir el trabajo nocturno (artículo 4 de ésta) de menores de 14 a 18 queda al arbitrio de las Juntas Locales y Provinciales de Reformas Sociales.

- La obligación de prestar 2 horas de educación primaria y religiosa para los menores de 14 años está igual en ambos textos; lo que aparecen en la ley (artículo 8 in fine de ésta) y que no está en el proyecto es la previsión de que los "niños que acrediten saber leer y escribir se les admitirá en la fábrica un año antes de la edad marcada" en la ley.

En este punto sí creemos oportuno explicar el sentido de este añadido, puesto que parece, a primera vista, que lo que hace la ley es permitir que los menores que sepan leer y escribir entren a trabajar un año antes, suponiendo, por tanto, un obstáculo para la continuación de la formación del menor obrero. Durante la tramitación parlamentaria $^{21}$, el diputado Ramon Auñón y Villalón cuestionó este añadido a lo que el diputado y miembro de la comisión encargada del proyecto, Antonio Orellana y Pérez Aloe, le aclaró que "se ha dado por supuesto en la comisión que los niños que reúnan aquella circunstancia (saber leer y escribir) están en condiciones de poder ganarse un jornal". Finalmente, el diputado Auñón afirmó que le parecía "muy bien ese premio que se les concede, permitiéndoles anticipar la edad de ganar un modesto jornal con que contribuir al sustento de la familia", pero concreta su oposición a los trabajos de dudosa moralidad, los peligrosos y a los que supongan dislocación y fuerza, en los que saber leer y escribir parece que pudiera ser "un riesgo que sólo pueden aceptar las familias como doloroso recurso para atender a necesidades extremas".

- En el proyecto no consta referencia alguna a la lactancia materna, mientras que en el artículo 9 de la ley aprobada, como es sabido, se incorpora la posibilidad que las

\footnotetext{
${ }^{21}$ Diario de Sesiones no 139 de 1 de marzo de 1900, pp. 4839 y ss.
} 


\section{IUSLabor 3/2018}

obreras dispusieran de 1 hora al día para amamantar sus bebés, divisible en dos medias horas, a voluntad de la madre y sin poder ser la hora descontable del salario.

Ello nos plantea la duda sobre la afirmación que realiza Bengoechea ${ }^{22}$ sobre que el proyecto de 30 de noviembre de 1899 era "mucho más proteccionista" que la ley aprobada. En algunos puntos, el articulado de la ley proponía mejoras respecto al proyecto; por tanto, como veremos, se podría matizar si la ley de 1900, aunque como veremos estuvo mal diseñada, fue un triunfo de las posturas más liberales.

- El artículo 10 del proyecto sí contempla la prohibición del trabajo durante las 3 semanas posteriores al alumbramiento, sin más; en cambio, el artículo 9 de la ley está más desarrollado y regula la reserva del puesto de trabajo ${ }^{23}$, así como el permiso laboral por lactancia del recién nacido.

- La exigencia de vacunación y de salubridad y de separación de sexos en los alojamientos de obreros facilitados por los patronos está en ambos textos. El detalle que sí es diferente es la imputación de las sanciones derivadas del incumplimiento de la norma: en el proyecto (artículo 14 de éste) no aparece la posible exoneración de responsabilidad de los patronos, que sí lo hace en la ley (artículo 13 in fine de ésta), respecto a que las sanciones serán solamente exigibles a los patronos, "salvo el caso de que resulte manifiesta la irresponsabilidad de los mismos".

- Finalmente, en el proyecto tampoco aparece ni la obligación del patrono de fijar la ley "en lugar visible de sus talleres" (artículo 17 de la ley), ni tampoco el carácter de pública de la acción para denunciar "los hechos que infrinjan" la norma (artículo 18 de la ley).

Según LLADÓ y VALLÉS ${ }^{24}$, el proyecto presentado por Eduardo Dato se fundamentaba en los protocolos de la Conferencia Internacional de Berlín de 15 de marzo de $1890^{25}$ en

\footnotetext{
${ }^{22}$ BENGOECHEA, S.; Los empresarios catalanes ante los proyectos de ley regulando el trabajo de las mujeres (1855-1912); en BORDERÍAS, C. (editora); Género y políticas del trabajo en la España contemporánea. 1836-1936; Història del Treball, no 2, Icaria Editorial, Barcelona, 2007, p. 101. Aunque en la página 110 matiza un poco su afirmación y concluye que 'en algunos puntos, la ley que acabó promulgándose el 13 de marzo de 1900 era mucho menos proteccionista que los proyectos elaborados a finales del año anterior'.

${ }^{23}$ Diario de Sesiones n ${ }^{\circ} 139$ de 1 de marzo de 1900 p. 4840.

${ }^{24}$ LLADÓ Y VALLÉS, J.; Información abierta por el 'Fomento del Trabajo Nacional' de Barcelona sobre el proyecto de ley regulando el trabajo de las mujeres y de los niños. Informe de Don Juan Lladó y Vallés. Abogado. Representante de la 'Asociación Democrática' de Madrid; Tipografía Española, Barcelona, 1900, pp. 15 y 16. De hecho, BORRÁs LlOP, Los límites..., op. cit, p. 164, entiende que las recomendaciones de la Conferencia de Berlín de 1890 sirvieron de fundamento para las bases de la
} 
la que participó el estado español, y en los que, entre otras materias, se proponía regulaciones sobre trabajo infantil: por ejemplo, se recomendaba la prohibición del trabajo de menores de 10 años para los países meridionales o de 12 años para el resto, sin discriminación de sexo; se proponía que los menores debían tener instrucción elemental, que los menores de 14 años no trabajaran de noche ni los domingos, ni que trabajaran más de 6 horas por día con descansos de hora y media; también se propuso la prohibición del trabajo de menores en industrias insalubres o peligrosas, etc. En dicha Conferencia también se propusieron ${ }^{26}$ regulaciones sobre el trabajo de jóvenes y mujeres, como por ejemplo la fijación de 4 semanas de descanso laboral después del parto, que verdaderamente eran muy similares al proyecto de ley presentado, por lo que parece que Lladó y Vallés estaba en lo cierto.

Si esta es una breve comparación entre el proyecto inicial presentado por Eduardo Dato y la norma finalmente aprobada, la tramitación parlamentaria intermedia también es interesante $^{27}$.

El proyecto de 18 de diciembre de 1899 fue remitido al Senado, que emitió el dictamen de la comisión encargada al efecto de fecha 22 de diciembre de $1899^{28}$, pero el mismo fue retirado de la sesión de 30 de enero de $1900^{29}$ por Francisco Javier González de Castejón y Elío, Marqués de Vadillo ${ }^{30}$, presidente de la comisión.

Según ha explicado BengoecheA ${ }^{31}$ y consta en la Memoria ${ }^{32}$ de Fomento del Trabajo Nacional de 1899, cuando esta institución tuvo conocimiento del proyecto de ley pidió al Presidente del Consejo de Ministros que dicho proyecto "se discutiera con calma tan trascendental materia, ofreciéndole abrir pública información para aquilatar el

Comisión de Reformas Sociales sobre el trabajo femenino de 1891, así como los proyectos de ley posteriores sobre la materia.

${ }^{25}$ RAMOS VÁZQUEZ, op. cit., pp. 354-355.

${ }^{26}$ Respecto al contenido de la Conferencia de Berlín de 1890, véase LowE, B.E.; The international protection of labor. Internacional labor organization, history and law; The Macmillan Company, New York, 1935, pp. 244 a 247. También EsPUNY TOMÀs, M.J.; El tiempo del trabajo: la ordenación histórica de una conquista laboral; Anuario de Historia del Derecho Español; nº 67, 1997, p. 1828.

${ }^{27}$ Sobre la tramitación, véase también MONTERO GARCÍA, op. cit., pp. 48 y ss.

${ }^{28}$ Apéndice $13^{\circ}$ del Diario de Sesiones de Cortes n ${ }^{\circ} 93$ de 22 de diciembre de 1899.

${ }^{29}$ Diario de Sesiones de Cortes n ${ }^{\circ} 117$ de 30 de enero de 1900.

${ }^{30}$ Sobre el Marqués de Vadillo, Caballero DomíngueZ, M.; MARCos del Olmo, M.; García EnCABo, C.; Las elites políticas en la provincia de Soria: los diputados a cortes en la restauración (1875-1923); Investigaciones históricas: Época moderna y contemporánea, 1995, N.15, pags.39-54.

${ }^{31}$ BENGOECHEA, S.; op. cit., págs. 97-126.

${ }^{32}$ Fomento del Trabajo NaCiOnal; Memoria (de 1899) leída en la Junta General Ordinaria de Socios celebrada el día 28 de enero de 1900; Tipografía Española, Barcelona, 1900, p. 9. 
concepto que a patronos y operarios merezca el proyecto", a lo que accedió el Presidente del Consejo suspendiendo la tramitación de proyecto de ley ${ }^{33}$.

BENGOECHEA $^{34}$ relata las opiniones mayoritarias contrarias al proyecto de ley que limitaba la libertad de trabajo de las mujeres, en base a la información obtenida por Fomento del Trabajo, resumida por Eusebio Passarrell Dirla en fecha 24 de enero de 1900 y que aparece en su revista El Trabajo Nacional no 15 de 10 de febrero de 1900. Además de la opinión del propio Passarrell, también constan la de otras 18 personas o representantes de asociaciones de obreros y patronos. No es objeto de este trabajo el estudio de estas opiniones, pero todas creen, por razones diferentes, que el proyecto de ley era malo porque no tenía en cuenta la realidad social de la época. Es decir, en resumen, que el trabajo infantil y femenino era una necesidad ineludible y que prohibirlo afectaba tanto a la competencia de las industrias españolas como a la subsistencia de las familias obreras. Como veremos en las Memorias de la inspección, no les faltaba razón.

Después de recibir la información de diferentes entidades, la comisión redactó un nuevo dictamen ${ }^{35}$ que, curiosamente, se inicia justificando su necesidad en su preámbulo: “[e]n vista de los nuevos e importantes datos que las autorizadas informaciones que por invitación del Gobierno de S.M. han aportado el Fomento del Trabajo Nacional de Barcelona, el Ateneo Obrero de Tarragona, la Liga Vizcaína, la Asociación General de Madrid para la defensa de la clase obrera, el Ateneo Obrero de Reus, el Sindicato de Fabricantes del Ter, el Ateneo Obrero y la Asociación de Fabricantes de Estampados de Barcelona, y la prensa, y oídas las opiniones de varios Diputados y distinguidos sociólogos, la Comisión [...] se ha creído en el deber de retirar el que tenía formulado y redactarlo en la forma que se expresa en el siguiente proyecto de ley".

Este segundo dictamen es parecido al articulado que finalmente tuvo la ley. Las únicas diferencias son las siguientes:

- Se mantiene el trabajo para menores de 10 años (artículo 1 del dictamen) siempre que trate del "aseo, la conservación y el cuidado de los locales donde se ejerza la

\footnotetext{
${ }^{33}$ Fomento Del Trabajo NACiOnAl; Memoria (de 1900) leída en la Junta General Ordinaria de socios, celebrada el día 27 de enero de 1901; Tipografía Domingo Casanova, Barcelona, 1901, p. 2: 'Deferentes el Gobierno de S.M. y el Sr. Presidente del Congreso a nuestro ruego, suspendieron la discusión de las citadas leyes (ley del trabajo de mujeres y niños y la ley de accidentes de trabajo) hasta conocer dicho informe; como más tarde fue consultado el Fomento al procederse a redactar los Reglamentos que debían regularlas; atención que nos mueve a pública gratitud, tanto por la deferencia que entraña, cuanto por el aprecio en que se tuvo nuestra modesta opinión sobre distintos extremos.'

${ }^{34}$ BENGOECHEA, op. cit, p. 103.

${ }^{35}$ Diario de Sesiones de Cortes no 122 de 6 de febrero de 1900 , apéndice $6^{\circ}$.
} 


\section{IUSLabor 3/2018}

industria y el comercio". Como ya hemos apuntado, en la ley la prohibición del trabajo a menores de 10 años será total.

- En el segundo dictamen no consta la limitación de 48 horas semanales del trabajo nocturno (artículo 4 in fine de la ley).

- Tampoco consta la prohibición del trabajo de menores de 16 años en "la limpieza de motores y piezas de transmisión mientras esté funcionando la maquinaria" (artículo 5.3 de la ley), que sí constará en la norma finalmente aprobada.

- En el segundo dictamen falta la prohibición del trabajo en domingo y festivo del artículo 6 in fine de la ley.

- Tampoco consta la previsión legal (artículo 7.3 de la ley) de que en las Juntas Provinciales de Reformas Sociales participe un "vocal técnico, designado por la Real Academia de Medicina, cuyo cometido será informar acerca de las condiciones de higiene y salubridad en los trabajos de los talleres".

- En el artículo 7.4 del segundo dictamen sí se otorga el carácter ejecutivo a las resoluciones de las Juntas Locales y Provinciales de Reformas Sociales respecto a las reclamaciones que obreros o patronos sometiesen a su consideración. En el texto de la ley desaparece este carácter ejecutivo.

- En el segundo dictamen no aparece tampoco el régimen del periodo de lactancia materna de las obreras que sí está contemplado en la ley (artículos 9.3, 4 y 5).

- El artículo 14 del segundo dictamen habla de la función inspectora del cumplimiento de la ley y la otorga al Gobierno, pero, a diferencia del artículo 14 de la ley, prevé la asistencia de "representaciones de la Juntas Locales, Provinciales y curas párrocos. El gobernador civil será el encargado de llevarla a cabo, pudiendo en casos extraordinarios y cuando la índole de los abusos lo reclamaren, nombrarse delegados especiales; pero siempre con facultades concretas y por tiempo determinado, no pudiendo en ningún caso crearse delegados o inspectores permanentes".

- Finalmente, en el dictamen no aparece como sí lo hace en el texto de la ley el carácter de público de la acción para denunciar los incumplimientos de la norma (artículo 18 de la ley).

De lo anterior se comprueba cómo entre el primer y el segundo dictamen se estableció el contenido final de la ley del trabajo de mujeres y niños de 1900. Finalmente, hubo un tercer dictamen, esta vez de la comisión mixta que debía "conciliar las opiniones de ambos cuerpos colegisladores" de fecha 2 de marzo de 1900, a escasos diez días de la aprobación de la ley. Este tercer dictamen tiene un articulado idéntico al de la ley que finalmente se promulgó. 
Para Bengoechea, el texto final de la norma fue un triunfo "rotundo" 36 de los patronos contrarios al intervencionismo estatal y partidarios del mantenimiento del trabajo de mujeres y niños con el mínimo de restricción posible. Además, señala que la ley finalmente otorgaba importantes funciones de inspección a las Juntas Locales, lo cual era valorado positivamente por los empresarios catalanes ya que esas Juntas estaban presididas por el alcalde de la ciudad, que presuponía afecto a los intereses patronales.

\section{Las Memorias de la inspección y la aplicación de la ley de mujeres y niños}

Pero este trabajo no quiere demostrar si los argumentos del sector patronal influyeron más o menos en la tramitación de la ley. De hecho, a la vista de las diferencias entre el primer, el segundo dictamen y la ley, podemos concluir que hay modificaciones favorables y desfavorables para los intereses patronales, es decir, variaciones que pudieran favorecer la protección de las mujeres y de los niños trabajadores y que la afirmación del éxito rotundo del empresariado catalán ${ }^{37}$ y de su influencia en Cortes podría ser refutada. Lo que queremos mostrar es si esta ley se incumplió y en qué medida.

Para ello nos hemos servido de las Memorias de la inspección de trabajo, que, como es sabido, se creó en mediante el Reglamento de la Inspección de Trabajo de 1 de marzo de $1906^{38}$.

Hemos priorizado esta fuente porque entendemos que en las Memorias debería constar la opinión de la inspección de trabajo, en tanto que organismo público encargado de expresamente de la inspección de la Ley del trabajo de mujeres y niños de 13 de marzo de 1900, según el artículo 1 del Reglamento de la Inspección de Trabajo.

Así, la información contenida en las Memorias se podría entender como, de algún modo, veraz, aunque evidentemente parcial, como hemos dicho al principio, sobre todo debido a la falta de personal y de medios con que nació la inspección de trabajo en el estado español. Respecto a la veracidad de la información que contienen las Memorias hemos de apuntar que entendemos que los inspectores encargados de recoger y remitir la información, así como el encargado de ordenarla y explicarla, no tenían ningún

\footnotetext{
${ }^{36}$ BENGOECHEA, op. cit., p. 110.

${ }^{37}$ De hecho, calificar de exclusivamente catalana la oposición al proyecto en base a la información recogida por Fomento del Trabajo Nacional también podría matizarse, ya que, en aquellos años esa institución no era exclusivamente catalana, sino que tenía capítulos en muchas ciudades españolas y además en la información recogida constan opiniones de abogados de Madrid, como Juan Lladó y Vallés, representante de la Asociación Democrática de Madrid, o de Alcoy, como Francisco de P. Juanico.

${ }^{38}$ Gaceta $^{\circ} 63$ de 4 de marzo.
} 


\section{IUSLabor 3/2018}

incentivo para desfigurar la realidad. ¿Qué incentivo podía tener un inspector que, seguramente, a principios de la inspección de trabajo era el único encargado de realizar su tarea en un basto territorio? ¿Qué ganaba si explicaba que la situación de las trabajadoras era peor que la real? De hecho, podríamos pensar que sí tenía cierto incentivo para dulcificar esa situación y no verse en la obligación de volver a visitar ciertas empresas o determinados parajes.

Veamos qué nos cuentas las Memorias de la inspección de manera cronológica, para comprobar si el paso de los años y el aumento de la capacidad inspectora redundó en un mayor cumplimiento de la norma sobre el trabajo de las mujeres y los niños de 1900.

Cabe tener en cuenta que la inspección se dividió en 8 regiones atendiendo al número de provincias que las forman y a su densidad industrial. La $1^{\text {a }}$ comprendía Madrid, Toledo, Guadalajara, Ciudad Real, Cáceres y Badajoz. La 2a , Barcelona, Tarragona, Lleida y Girona. La 3ª Vizcaya, Álava, Gipuzkoa, Santander y Logroño. La 4ª Oviedo, Coruña, Lugo, Orense, Pontevedra y León. La 5a , Sevilla, Huelva, Cádiz, Córdoba, Jaén, Granada, Almería y Málaga. La 6 ${ }^{\mathrm{a}}$, Valencia, Alicante, Castellón, Cuenca, Albacete y Murcia. La 7 , Burgos, Valladolid, Zamora, Palencia, Ávila, Salamanca y Segovia. Y la $8^{\text {a }}$, Zaragoza, Huesca, Teruel, Navarra y Soria; además, había un inspector provincial para Baleares y Canarias, respectivamente ${ }^{39}$. También expondremos lo que cuentan las Memorias a partir de esta división territorial; de hecho, la información que muestran las Memorias bien podría utilizarse de manera mucho más concreta y obtener la situación del trabajo en zonas más concretas del territorio.

Además, veamos cómo justificaba la misma inspección el cumplimiento o no de la norma. Veamos qué relatos existen en las Memorias sobre el trabajo femenino y el trabajo infantil en la España de los primeros quince años del siglo pasado.

\subsection{Memoria de $1907^{40}$}

Los inspectores explican que los telares a mano, cordelerías, zapaterías y fábricas de sombreros que existían en la provincia de Badajoz eran competitivos "gracias a enormes jornadas y al empleo de mujeres y niños, que cobran escasísimos jornales" (p. 23). También concretan que "en Madrid, los talleres de modistas, pasamanería,

\footnotetext{
39 InSTITUTO DE REFORMAS SOCIALES; Memoria del servicio de inspección en 1907; Imprenta de la sucesora de M. Minuesa de los Ríos, Madrid, 1908, pp. 15 y 16.

${ }^{40}$ InSTITUTO DE REFORMAS SOCIALES; Memoria del servicio de inspección en 1907; Imprenta de la sucesora de M. Minuesa de los Ríos, Madrid, 1908. Para agilizar la lectura y evitar un enorme número de notas a pie de página, hemos indicado entre paréntesis el número de la página de la Memoria de donde se ha obtenido el texto transcrito.
} 


\section{IUSLabor 3/2018}

encuadernación y alguna fundición tipográfica, falta a lo preceptuado en la Ley del trabajo de mujeres y niños: la campaña de inspección durante el 1908 se dedicará principalmente a esos centros" (p. 26) y respecto a las imprentas de Madrid (p. 40) concreta que "infringen la Ley de mujeres y niños, y que comenten numerosas faltas de higiene y seguridad".

El apartado VI de la Memoria de 1907 se centra en el trabajo de mujeres y niños y textualmente (p. 40) dice, después de 8 años de vigencia, que "la Ley de 13 de marzo de 1900, reguladora del trabajo de las mujeres y de los niños, no puede decirse que haya entrado aún en vigor en algunas zonas de la Península, cumpliéndose mal o no cumpliéndose en casi toda ella. En la primera región, por ejemplo [...] es infringida escandalosamente en la casi totalidad de la provincia de Badajoz, pero donde ofrece caracteres intolerables es en Castuera, Don Benito, Llerena y Azuaga. Se pretende en estas poblaciones que los telares a mano, las cordelerías, zapaterías y fábricas de sombreros, luchen con las fábricas y talleres modernos, a expensas de jornadas de 12 a 14 horas de trabajo y de jornales de 0 "25 a 1 peseta, entregados a mujeres y niños, trabajando las mujeres de 14 a 20 años a destajo en los telares a mano y cordelerías, burlando así la ley [...]". En total, en esa región se contabilizaron 923 infracciones de la Ley de mujeres y niños, que iban desde la existencia de menores de 10 años en las fábricas (9 casos) a la falta de la documentación relativa a la vacunación (127 casos). Para la inspección, la cifra de 923 infracciones era "enorme (y) que demuestra la necesidad absoluta de la inspección y los resultados que de la misma pueden esperarse por la corrección de un estado de cosas enteramente anárquico y lamentable".

También aparece en la Memoria la relación de espectáculos públicos denunciados por el incumplimiento de la prohibición de los menores de 16 años de participar en trabajos de agilidad, equilibrio, fuerza y dislocación (artículo 6 de la ley). Al respecto, la Memoria explica (p. 44) que la inspección había actuado en este ámbito "abrigando vehementes sospechas de que existía una confabulación entre los empresarios y los artistas, que daba por resultado el no vacilar en falsificar los documentos presentados al inspector". Parece claro que ambas partes de la relación laboral en este sector estaban de acuerdo en el incumplimiento de la ley, en seguir utilizando menores en los espectáculos públicos.

Respecto a la $2^{\mathrm{a}}$ región configurada por las provincias catalanas, la Memoria no deja lugar a dudas (p. 76): "[s]i en todas las regiones de España esta ley es infringida, en Cataluña lo es con unos caracteres que obligan a la Inspección a proponerse corregir las escandalosas faltas con severidad, porque el número de menores empleados en las fábricas es tan considerable, que no puede consentirse tan absoluto incumplimiento de la Ley". Y pone ejemplo: "[e]n las fábricas de hilados de algodón trabajan un gran número de menores [...] lo mismo sucede en casi todas las fábricas de hilados y tejidos 


\section{IUSLabor 3/2018}

situadas sobre los ríos Ter, Fresser y Fluvià, y también en las fábricas de Manresa y Martorell, situadas sobre el río Cardener".

Pero es interesante que los modos de evitar la inspección también consten en la Memoria: "[n]o es posible fijar el número de infracciones al artículo 2 de la Ley de 13 de marzo de 1900, porque en algunas fábricas, cuando se presenta el inspector de trabajo, hacen salir, si se les da tiempo, a los menores de edad; en otras se les avisa para que no se presenten en la fábrica mientras permanezca el inspector en la localidad visitada, y en otras, en fin, se les enseña a contestar a las preguntas de los inspectores, respondiendo con arreglo a lo que la ley exige, pero no la verdad". Por ello, la inspección concluye que (p. 80) "la industria textil se presta al empleo de menores en condiciones ilegales y ha de ser objeto de atención muy constante $y$ preferente por parte del servicio de inspección".

En la $3^{\text {a }}$ región se hace constar que (p. 100) "en todos los establecimientos y fábricas visitados donde trabajan mujeres y niños están incumplidos en absoluto" la obligación de que "el trabajo que han de efectuar no es superior a sus fuerzas, que no padecen enfermedad contagiosa e infecciosa y que están vacunados en época oportuna". Además, se reitera que (p. 102) "la industria en la que se cumplen peor las prescripciones legales sobre trabajo de los menores de 14 años es en la de tejidos".

Incluso consta que el propio inspector regional ofreció a los patronos de determinadas empresas textiles "disminuir paulatinamente en esas fábricas el número de infracciones observadas [...] aumentando el número de niños obreros para reducir proporcionalmente el número de horas de trabajo hasta llegar a las 6 que ordena la ley, o sustituyendo a aquéllos por mayores de 16 años o por adultos. Esta modificación no puede hacerse de una sola vez, por encontrarse esas fábricas establecidas en lugares de reducida población, siendo seguro que una medida brusca habría de producir graves perjuicios para su marcha normal".

Para entender esta proposición del inspector es imprescindible hacer notar que lo que establece el artículo 21 del Reglamento de Inspección de 1 de marzo de $1906^{41}$ sobre cómo debía actuar el inspector de trabajo, que en ningún momento debía perjudicar a la industria (el destacado es nuestro):

"La misión de los Inspectores debe tener un carácter preventivo, tanto como represivo. La legislación se dirige a proteger al obrero, pero sin causar vejaciones a la industria, y los Inspectores habrán de inspirarse en este concepto, sin desposeerse de la autoridad que es aneja é indispensable al cumplimiento de sus deberes."

\footnotetext{
${ }^{41}$ Gaceta $^{\mathrm{o}} 63$ de 4 de marzo de 1906.
} 
El inspector propuso en 1907 una manera de poder cumplir la Ley de mujeres y niños de 1900, sin que dicho cumplimiento pudiera ocasionar daños relevantes a la industria inspeccionada.

Finaliza la región $3^{\mathrm{a}}$ mencionando (p. 104) que "en la provincia de Gipuzkoa, el trabajo de los menores es general en casi todas las industrias, y siempre a petición de los padres, que encuentran en esto un procedimiento cómodo para reforzar sus ingresos". Más allá del manifiesto cinismo de las palabras (“cómodo") lo cierto es que, de la frase transcrita, se podría concluir que el trabajo infantil era una necesidad para las familias, no tanto un capricho, y que el incumplimiento voluntario de la ley estaba fundamentado en la subsistencia familiar. Si pasados 7 años desde la promulgación de la ley y ésta era voluntariamente incumplido por aquellos a los que protegía debido a su inherente necesidad para vivir, podríamos concluir que era una norma que no se adaptaba a la realidad social del momento y que, además, posiblemente no estaba bien hecha: ¿qué incentivos provocaba en los padres para que, racionalmente, prefirieran incumplir la norma que cumplirla, cuando era la necesidad y el hambre lo que condicionaba su conducta?

En la $4^{\text {a }}$ región (Galicia, Asturias y León) el cumplimiento de la ley es similar a las anteriores: (p. 117) "son muy raras las industrias en las que no se encuentran ocupados menores de 14 años sin limitación alguna en el número de horas de trabajo" pero parece que el límite de la jornada oficial de trabajo sí se cumplía.

Sorprende la explicación de la Memoria de 1907 sobre la 5a región, la andaluza, que tenía "una densidad industrial pequeña". En este punto es esencial tener en cuenta que la Ley de 13 de marzo de 1900 no sólo se refiere al trabajo de mujeres y niños en industrias, ya que, por ejemplo, su artículo 1 se refiere a la prohibición del trabajo de menores de 10 años "en ninguna clase de trabajo". Pero parece que la inspección de esta región se centró en "los centros industriales más importantes", aunque sí constan como visitados 5 industrias "forestales y agrícolas" (p. 124). Además, consta que el mayor contingente obrero de niños estaba en la industria textil y forestal, y en ésta es donde "emplean niños más pequeños" de 14 años (p. 134).

La Memoria también cuenta (p. 145) que "es tan escaso el número de establecimientos donde se observa con todo rigor la Ley de 13 de marzo de 1900, que puede decirse se halla incumplida totalmente en algunas industrias y casi por completo en las más". Las industrias metalúrgicas sí cumplían con la norma, a excepción de "algunas fundiciones de plomo del término de Linares, donde hay menores de 14 años". 
Pero (p. 145) en "las industrias forestales y agrícolas son las que dan contingente mayor a las infracciones"; así, se menciona los graves incumplimientos de la industria del "empacado de esparto" de Almería que "hállase clasificada entre las nocivas, pues se realiza en una atmósfera cargada de partículas minerales, filamentos de esparto, semillas y corpúsculos vegetales que determinan frecuentes afecciones en los ojos, tanto más lamentables cuanto que se ceban en niños y mujeres de 10 a 16 años, los cuales constituyen más de las tercera parte de la masa obrera consagrada a tal trabajo. Estos efectos se agravan con la desmedida extensión de la jornada, que es de 12 horas. Análogas observaciones deben hacerse sobre la industria del embarrilado para las uvas de embarque, género muy extendido en la citada región almeriense".

Además, señala que "en casi todos los centros de esa clase de trabajo (forestal y agrícola) ha comprobado el inspector la existencia de niños entre 10 y 14 años, y cabe suponer que el abuso llegue al punto de utilizar el trabajo de algunos menores de 10 años, dada la dificultad de puntualizar la edad en algunos casos".

De ello se concluye que las industrias agrícolas y forestales, las más numerosas en Andalucía, eran, además, las que más incumplían con la prohibición del trabajo infantil.

Respecto a esta región se da cuenta de las industrias insalubres como las textiles, por el polvo del algodón y porque la extracción de la seda provoca enfermedades pulmonares y la llamada "mal de los gusanos" 42 . También cita el riesgo de fosforismo en las industrias cerilleras o las industrias del vidrio, por el polvo que desprenden, en las que se usan niños menores de 16 años (p. 147).

Finalmente, se cita que el plazo de 2 horas para la instrucción de los niños "no está(n) en práctica: excepcionalmente se encuentra algún centro de trabajo que costea escuela para los menores".

\footnotetext{
${ }^{42}$ En relación al 'mal de los gusanos' es muy interesante el documento del Instituto de Reformas Sociales titulado 'Visita de inspección a la fábrica de sedas de Ugíjar', localidad de la parte suroriental interior Almería, redactado por Florencio Porpeta y Llorente, publicado por la Imprenta de la sucesora de M. Minuesa de los Ríos, en Madrid, el 1905, es decir, dos años antes de la Memoria de 1907. Ese mal consistía en una afección cutánea que también se la conocía por 'sarna de las hilanderas', causada por la inmersión de las manos en agua caliente cargada de materias orgánicas y de la 'substancia aglutinante del capullo'. El trabajo de las hilanderas consistía en ir desenrollando los hilos de los capullos reblandecidos en flotaban en agua caliente. En el informe se concreta que de las 65 trabajadoras sólo se pudo examinar a 58 , de las que sólo 25 declararon haber sufrido estos accidentes cutáneos. Pero este informe también contempla el incumplimiento de la Ley de mujeres y niños de 1900, respecto a la edad y la jornada de las trabajadoras.
} 


\section{IUSLabor 3/2018}

En la $6^{\text {a }}$ región (Valencia, Albacete, Alicante, Castellón, Cuenca y Murcia) la mayoría de los niños estaba empleada en la industria del vestido (p. 191); además, menciona expresamente que "se ha podido apreciar en los centros visitados la eficacia de las Juntas Locales de Valencia, Alicante y Alcoy", y respecto al trabajo de la mujer "no se han advertido infracciones de la ley", por lo que "se puede decir que, en general, se cumple bien la ley" (p. 210). Aún y así, en la Memoria consta un informe del inspector sobre la industria lanera de la localidad de Bocairent en la que sí trabajan menores de 10 años y sobre las malas condiciones de la industria del timbrado con purpurina de los envoltorios de los cítricos.

Lo anterior nos da pie a comentar la parcialidad de la información que se expone en las Memorias. El inspector concluye que, en general, se cumple la ley, pero lo cierto es que únicamente visitó 272 industrias de toda la región (p.157), la cual incluye 6 provincias con perfiles industriales muy diversos. Nada tenía que ver la ciudad de Valencia con la huerta murciana o el interior de Albacete, por lo que intuimos que de la visita a 272 empresas sería difícil concluir que la ley se cumplía de forma general.

Desde otro punto de vista, el informe sobre el timbrado con purpurina del papel para envolver naranjas (págs. 211 y ss) es un ejemplo de la información suplementaria, del relato, que se puede extraer de las Memorias. A este tipo de industria, muy especializada, se dedicaban la mayor parte de las imprentas de la zona de Valencia y Castellón, algunas casi en exclusiva. La tarea era dorar con purpurina, a máquina o a mano, el papel ya timbrado de diferentes marcas de cítricos dedicados a la exportación, sobre todo hacia Londres y era un trabajo fácil de aprender y con buen salario.

De resultas del inicio de un expediente en la Junta Local de Reformas Sociales de Valencia, el inspector tuvo conocimiento que lo nocivo de la tarea era el polvo usado para dorar; de hecho, explica que en la visita a uno de los talleres el ambiente estaba tan cargado de polvo que "salimos con ropa, sombrero y botas, doradas". A lo que el inspector recomendó verbalmente en este y otros talleres el uso de mascarillas y gafas protectoras.

El inspector (p. 215) "al preguntar a cualquier de ellos (trabajadores), hombre o mujer, todos, sin excepción, contestaban que aquello era muy sano, que estaban muy contentos, y es que todos estaban sugestionados por las conveniencias a cambio de un quebranto evidente de su salud". Por ello, el inspector abogaba porque "lo antes posible se instalen máquinas de purpurinar, quedando proscrito el purpurinado a mano, por ser evidentemente nocivo para la salud del obrero, que la pierde quizás para toda su vida sólo por mayor salario en un período que no pasa de cuatro a seis meses en cada año”. Estas palabras muestran hacia cierto punto el paternalismo con el que partían los 


\section{IUSLabor 3/2018}

inspectores, ya que parece que no se planteaban que la ejecución de dicho trabajo lo realizaban los trabajadores por estricta necesidad y no por la simple y posiblemente irónica alegría que le manifestaban los trabajadores.

El inspector de la región $7^{\text {a }}$, que accedió a su puesto a finales de agosto del 1907, comenta (p. 261) que "en cuanto al trabajo de mujeres y niños, son pocas las infracciones que el inspector ha podido observar, debido al corto número de visitas efectuadas (60) y a la reducida masa obrera incluida en estas categorías legales". Reiteramos: es importante reseñar la parcialidad de las primeras Memorias de la inspección.

Y respecto a la región $8^{\mathrm{a}}$ el inspector comenta (p. 266) que "solo en tres establecimientos de los visitados trabajan" mujeres o niños, y cita el circo en el que el trabajo de los menores estaría prohibido, la Azucarera de Aragón y un taller de guarnecido de cortes, en ambos casos cabía mejorar las condiciones laborales de las mujeres.

El comentario del inspector de trabajo de las Islas Baleares que consta en la Memoria (p. 270) es del todo ilustrativo de la realidad de las cosas en el trabajo infantil de principios del siglo XX: "los patronos repugnan disminuir el número de horas (de los niños), pretextando el mal efecto que causaría en los demás operarios, los cuales persiguen la reducción de su jornada". Ante la insistencia del inspector de cumplir la ley, se ha comprobado que "muchos fabricantes (estaban) inclinados a prescindir del trabajo de los menores, lo cual, de realizarse, redundaría, por el pronto, en perjuicio de aquellos a quienes la ley quiere proteger, pues las familias respectivas veríanse privadas del socorro que les procura el trabajo de los referidos menores. De aquí la conducta prudente que se impone para conseguir el resultado que la ley persigue". Las propias palabras del inspector nos ponen un espejo delante: el trabajo infantil estaba íntimamente relacionado con la necesidad, y si no se evitaba, aun y prohibido, era por la subsistencia familiar. ¿Estaba la Ley de 1900 bien diseñada si no tenía en cuenta este hecho? ¿Qué proponía la norma para poder aminorar el efecto no deseado de la ley, como era la disminución de los ingresos familiares? Nada. Seguramente por eso la ley no consiguió el objetivo buscado.

\subsection{Memoria de $1908^{43}$}

La palabras con las que se inicia la Memoria son del todo ilustrativas de la situación de la clase obrera en 1908 y de la realidad con la que la Ley de 1900 no se podía adaptar

\footnotetext{
${ }^{43}$ InSTITUTO DE REFORMAS SOCIALES; Memoria general de la inspección de trabajo correspondiente al año 1908; Imprenta de la sucesora de M. Minuesa, Madrid, 1910.
} 


\section{IUSLabor 3/2018}

(p. 9): "la casi totalidad de los talleres de España utilizaban el trabajo de las mujeres o de los menores fuera de los términos legales" y lo justifica apelando a la competencia de la industria extranjera sobre la española: "no la permitía (a la industria española) desafiar la concurrencia de la producción extranjera, el elemento patronal pugnaba por robustecer su respectiva industria, y no lográndolo por la perfección en los procedimientos tecnológicos, hallaba más fácil conseguirlo por la economía de los jornales, utilizando el trabajo de las mujeres y tomando de los menores, a bajo precio, una energía indispensable a su desarrollo físico, sin parar mientes en la miseria fisiológica de la juventud y en los peligros para el porvenir de la raza. La obligación cultural, impuesta a los patronos en favor de los. menores, yacía casi absolutamente incumplida; los teatros y circos, con lamentable frecuencia, ofrecían el espectáculo público de menores entregados a ejercicios impropios de 'su edad y peligrosos para su moral; en no pocos talleres veíanse niños de diez años, y aun de más corta edad; había menores trabajando en industrias insalubres y peligrosas, y a veces no existía siquiera en los talleres la debida separación de sexos". Con ello se muestra que los patronos tampoco tenían ningún incentivo a cumplir la norma: según estas palabras, que cabe recordar son de un inspector de trabajo, los patronos sólo podían competir con el mercado internacional mediante el incremento de competitividad derivado de los bajos salarios de mujeres y niños.

En lo que respecta a las diferentes regiones, la manera de exponer los datos cambia substancialmente de la Memoria de 1907 y, en determinadas regiones, únicamente aparecen datos estadísticos, sin un redactado explicativo de las diferentes infracciones de la ley de mujeres y niños. No es objeto de este primer capítulo del trabajo el análisis de los datos estadísticos, sino que nos interesa explicar el relato que utilizó la inspección de trabajo respecto al incumplimiento de la ley de mujeres y niños de 1900. Dejamos para el último capítulo el análisis estadístico, que ya podemos advertir que arroja datos muy interesantes sobre dicho incumplimiento.

En la región $2^{\mathrm{a}}$ referente a Catalunya se cuenta (p. 72) que "los patronos fundan el incumplimiento de la ley de mujeres y niños (en lo que se relaciona con el trabajo de menores) fingiendo amparar a la clase obrera con el auxilio del jornal que da al niño, y en otros casos en la clase de labor a que los destina, la cual, por su índole, no es propia de obreros adultos". Entre los patronos incumplidores están los del sector del "vidrio y similares, que necesitarán del empleo de medios coercitivos para llegar al cumplimiento de la Ley, pues se ha observado que emplean la resistencia pasiva, de acuerdo entre los que forman hoy el trust de estas industrias. En casos análogos se hallan las fábricas de cajas de cartón, las de hilados y otras menos importantes". Al respecto, hay que señalar que el sector del vidrio era una industria con una gran feminización de las tareas, con exclusión de formación en los trabajos más bien 


\section{IUSLabor 3/2018}

pagados, como era el soplido del vidrio ${ }^{44}$. Así, se nos encontramos con las recién llegadas bombillas eléctricas, el vidrio decorado, etc.

De hecho, aunque el artículo 1 del Decreto de 25 de enero de $1908^{45}$ prohibiera el trabajo de menores de 16 años de ambos sexos y de mujeres menores de edad en la industria del "vidrio y cristal de todas clases" por "riesgo de intoxicación o por producirse vapores o polvos nocivos para la salud", lo cierto es que la contratación creció en esta industria ${ }^{46}$.

La Memoria sigue explicando (p. 85) que el salario de la mujer es "indispensable [...] (y) a la reunión de varios salarios en una misma casa, lo cual es muy frecuente [...]. La ley que las ampara (a las mujeres) es excelente, de cumplirse con rigor; pero es muy difícil averiguar si existen infracciones al no mediar, delación espontánea de su parte, y éstas no son frecuentes por el temor de ser despedidas". Vemos como la inspección parece fiar la aplicación de ley a las denuncias de las obreras, más que al éxito de las visitas de los inspectores. Además, se da cuenta que la delación es infrecuente por el carácter de indispensable del salario femenino para el hogar. Lo curioso de ello es que, aunque el inspector intuye donde está el quid (en la necesidad y la subsistencia), yerra cuando ignora que la norma que ha de hacer cumplir no está bien diseñada.

Hace constar en la misma página de la Memoria que "en los centros visitados se acatan fielmente las prescripciones relativas a la lactancia y al embarazo", pero "es frecuente encontrar la infracción a la ley, en lo que se relaciona con el trabajo de menores, durante mayor número de horas que las que permite aquélla. Las certificaciones de nacimiento, que justificarían la edad de los obreros empleados, no las tienen en la mayoría de las fábricas, y, según parece, se niegan a expedirlas gratis en los Registros civiles". ¿Por qué la ley no previó que el coste de obtener la certificación de nacimiento podría ser un coste real para la clase obrera y, por tanto, un obstáculo para el cumplimiento y un incentivo para la picaresca?

\footnotetext{
${ }^{44}$ Según BALCElls, A.; Les dones treballadores a la fábrica i al taller domèstic de la Catalunya del segle XIX i primer terç del XX; Catalan Historical Review, $\mathrm{n}^{\circ}$ 8, 2015, p. 175, hacia 1915-1920 en la industria del vidrio las mujeres representaban el 20 por ciento de la mano de obra e incluso existían oficios enteramente femeninos, como la fabricación de bombillas eléctricas, la decoración del vidrio y el sector de las vestidoras de garrafas. Al respecto, también IBARZ, J.; Con gesto viril. Política sindical y trabajo femenino en la industria del vidrio en Barcelona, 1884-1930; en BORDERÍAS, C.; Género y políticas del trabajo en la España contemporánea: 1836-1936; Icaria, Barcelona, 2007, pp. 195 a 199, da cuenta detallada de las circunstancias del trabajo femenino en la industria del vidrio catalana.

${ }^{45}$ Gaceta ${ }^{\circ} 27$ de 27 de enero de 1908.

${ }^{46}$ NASH, M.; Trabajadoras: un siglo de trabajo femenino en Cataluña, 1900-2000; Generalitat de Catalunya, Departament de Treball, Barcelona, 2010, p. 24.
} 


\section{IUSLabor 3/2018}

Al respecto es muy interesante lo que hace notar Espuny ${ }^{47}$ : la ley francesa de 2 de noviembre de 1892 "sur le travail des enfants, des filles et de femmes dans les établissements industriels" contemplaba la gratuidad de los certificados de nacimiento ("livret”) que expedía el alcalde de la localidad, así como del certificado del médico que acreditaba las correctas aptitudes físicas del menor para el trabajo contratado.

Curiosa es la afirmación de que "con el nombre de aprendices se pretende por algunos patronos burlar la Ley, y en caso análogo se hallan los establecimientos benéficos y los talleres Salesianos", es decir, que esconden aprendices que podrían suponer el incumplimiento de la ley. Se menciona también en cumplimiento de la prohibición del trabajo nocturno en Barcelona, mientras se incumple "fuera de ella, especialmente en algunas fábricas de hilados".

Se certifica que "en ninguno de los centros visitados facilitan instrucción primaria y religiosa; no exhiben certificados ni de nacimiento ni de vacunación; no presentan permiso paterno, ni hay tampoco separación de sexos". Así, se nos presenta un incumplimiento reiterado y general al respecto, pero ¿qué coste podría tener obtener estos certificados médicos de vacunación?

Y finalmente se hace constar que las fábricas de hilados y de papel son las industrias que más incumplen la prohibición del trabajo de menores en las industrias clasificadas por el Real Decreto de 25 de enero de $1908^{48}$, antes citado.

Respecto a la $3^{\mathrm{a}}$ región se comenta (p. 118) "la superioridad de Vizcaya sobre Guipúzcoa, y principalmente sobre Logroño, en lo que respecta al cumplimiento de la Ley de mujeres y niños"; en la primera constan pocas infracciones en comparación con las otras dos provincias. Según la Memoria la causa está en que "las reformas sociales han entrado de lleno en la masa obrera, pudiéndose afirmar que serán pocos los obreros que no sepan la esencia de las Leyes de Accidentes, de mujeres y niños y de Descanso dominical". Según la Memoria, el "grado de cultura de la clase obrera" en Vizcaya era superior a las otras dos provincias, lo que justifica el cumplimiento de las normas protectoras. Las frases transcritas también son interesantes porque nos permiten conocer un relato sobre un incremento de la conciencia de clase en el País Vasco respecto a otros territorios, siendo sinónimo de dicho incremento de la conciencia el conocimiento de las leyes protectoras de los obreros.

\footnotetext{
47 ESPUNY TOMÁS, M.J.; La primera legislación social protectora de la mujer: una perspectiva comparada; en RAmos VÁZQUEZ, I. (coordinadora); Derecho y Trabajo en el Siglo XIX; Dykinson, Madrid, 2017, pp. 108 a 116.

${ }^{48}$ Gaceta ${ }^{\circ} 27$ de 27 de enero de 1908.
} 


\section{IUSLabor 3/2018}

Escapa del objeto de este trabajo analizar si lo anterior es cierto, es decir, en qué medida el conocimiento de las primeras leyes laborales supuso la nacimiento y desarrollo de la conciencia de clase. ¿Podríamos afirmar que verse como destinatario/beneficiario de una ley laboral podría incrementar dicha conciencia de clase, en tanto que presuponía determinadas dicotomías (pe. no ser beneficiario de la ley antes, sí serlo a partir de la norma presupone una situación injusta anterior; ser beneficiario de la ley versus no ser beneficiario de ley presupone que un sujeto sufre una situación que la ley quiere corregir y otro que no la sufre o que incluso se beneficia de ella; ser beneficiario de la ley supone identificarse como sujeto titular de derechos subjetivos; etc.).

Es curioso cómo los patronos de esta región justificaban el incumplimiento de la prohibición de trabajo de menores en las industrias relacionadas en el Real Decreto 25 de enero de 1908 antes mencionado: los oficiales mayores de 16 años eran "difíciles de educar" (p. 124) y por eso usaban menores en esos trabajos prohibidos.

En la $4^{\text {a }}$ región (Oviedo, Coruña, Lugo, Orense, Pontevedra y León) el trabajo de mujeres "se practica, en general, en condiciones legales" (p. 136) y cuenta que la mujer "aquí lo es todo [...] debido a la carencia absoluta de bracero hombre ${ }^{49}$ [...] la razón de ello no es otra que la constante emigración del hombre a otros países en busca de mayor salario".

En la región andaluza $\left(5^{\mathrm{a}}\right)$ existía una importante industria azucarera que hacía que en los meses de marzo, abril y mayo, en determinadas localidades se encontraran trabajando "hombres, mujeres y niños de toda edad y condición" (p. 167), es decir, estamos ante un trabajo esencialmente estacional. Además, señala que, en las industrias sevillanas de tabacos, cerillas, tejidos, tampones y objetos de corchos, de esencias, sombreros, loza, cajas de envases de lata, etc. "suman algunos miles de mujeres y niños en sus talleres", por lo que "se reclama una especial atención".

Concretamente, (p. 169 y ss) se menciona que "sólo se han encontrado cuatro fábricas en donde hubiera menores de 10 años, siendo bastante el número de los que se hallaban en este caso en el año anterior". Respecto a los mayores de esa edad, la Memoria comenta que los patronos prefieren despedirlos "a que trabajen 6 horas

\footnotetext{
${ }^{49}$ Rial GaRCíA, S.M.; Trabajo femenino y economía de subsistencia: el ejemplo de la Galicia moderna; Manuscrits, $\mathrm{n}^{\circ} 27,2009$, p. 81, ya nos habla del problema de la emigración masculina ya en época moderna y de las 'viudas de vivos', es decir, de mujeres casadas cuyos maridos habían emigrado de manera más o menos definitiva que se encargaban del trabajo campesino o del trabajo artesano en las ciudades. A ello podríamos añadirle la menor alfabetización de las mujeres gallegas trabajadoras, en relación con los hombres, en MARTínez DOMínGUEZ, B.; La formación del capital humano en Galicia (1860-1900): alfabetización y atraso económico; Revista Galega de Economía, volumen 12, número 1, 2003, pp. 6 y ss.
} 
interrumpidas por descansos [...] y a que dediquen 2 horas a instrucción primera y religiosa", aunque en algunas fábricas sí se reordenó el trabajo de esos menores.

Parece que el mayor número de incumplimientos de la norma fue la falta de exigencia de los patronos de los certificados de vacunación ni el permiso paterno de los menores trabajadores, necesario para poder ser admitidos en el puesto laboral. Para el inspector “más que por mala fe, es por ignorancia o apatía, en la mayor parte de los casos, por lo que no se cumplen estos preceptos". Por ello, explica que en la mayoría de los casos existía una buena disposición de los patronos para el cumplimiento de la ley, una vez ésta se les explicaba, y sólo se encontraron dos casos de resistencia patronal en su cumplimiento, concretamente en dos fábricas cerilleras de Sevilla.

En la $7^{\text {a }}$ región (Castellón, Valencia, Alicante, Cuenca, Albacete y Murcia) la mayor parte de infracciones derivaban del escaso cumplimiento de la limitación a 6 horas de los menores de 10 a 14 años (p. 222).

Es muy curiosa la afirmación del inspector (p. 224) sobre que "ofrece grandes dificultades el cumplimiento exacto" de la ley obviando si es justa, si es jurídicamente correcta o si es moralmente adecuada. Y su dificultad radica en "lo muy extendida que está [...] la ocupación de los menores y la conjunción de intereses patronales y obrero que en ello están empeñados". Se reconoce que existe un interés por ambas partes del contrato laboral en mantener el trabajo infantil, pero no se entra en el por qué de ese interés o (mejor dicho) de esa necesidad. Las industrias que más utilizaban el trabajo infantil eran las de tejido de lana, alpargatas, de hilados de seda, cáñamo, construcción y cerámica.

Relata el hecho que algunos patronos veían difícil organizar la jornada para que los menores de 14 años sólo trabajaran 10 horas, llegando alguno incluso a amenazar a despedir de inmediato a todos los menores de 14 años, "solución que no aceptó, entendiendo que habría de perturbar a buen número de familias obreras por modo violento, con gran lesión de legítimos intereses, que no podría cargarse a la cuenta de la inspección y de la ley". Es decir, que la propia inspección conocía que el trabajo infantil era fruto de la necesidad de la clase obrera y no quería cargar con "la culpa" de perjudicar a las familias de los menores trabajadores.

También se explica que la mayoría de la industria alpargatera ${ }^{50}$ es un ejemplo de trabajo a domicilio, "de forma que no es posible intervenir, pues constituyen talleres de familia

\footnotetext{
${ }^{50}$ MiRANDA ENCARNACIÓN, J.A.; De la tradición artesana a la especialización industrial. El calzado valenciano, 1850-1930; Revista de Historia Industrial, $\mathrm{n}^{\circ}$ 4, 1993, p. 21, comenta que hacia la década de 1880 la industria alpargatera valenciana ya usaba masivamente empleo de mujeres y niños, y que las fases
} 


\section{IUSLabor 3/2018}

muy numerosos" (p. 226). Sobre la industria del cáñamo, yute y esparto, se explica que es donde abundan los menores de 10 y de 10 y de 14 años trabajando, que son "pequeños grupos aislados o talleres compuestos por un hilador y dos o tres auxiliares que son menores de 14" o de 10 sobre los que es difícil intervenir. Igualmente, respecto a la industria agrícola de los "trencaors", o descarcaradores de almendras, en las que trabajaban tanto mujeres como menores.

En la $7^{\mathrm{a}}$ región (Valladolid, Salamanca) "a primera vista, se observa que no trabajan menores de 10 años, debiéndose este hecho a la acción de las sociedades obreras de resistencia, que no permiten el trabajo en fábricas, no sólo a esos menores, sino a todos los que no hayan cumplido 14 años" (p. 248).

Se cuenta que en todos los centros de trabajo de Béjar se incumple la obligación de presentar certificado de vacunación, "a pesar de cuidado y celo que observa la Inspección. Existe gran repugnancia en esta clase obrera para la vacunación, y por ello la Inspección se ha dirigido de oficio a los Presidentes de las Sociedades obreras, rogándoles influyan sobre los miembros que las constituyen para que cumplan con lo que de modo terminante manda la Ley, pues de otro modo se verá en el caso de no tolerar su incumplimiento en las próximas visitas" (p. 250), sin que se mencione el coste de la obtención de dichos certificados.

Respecto a la figura de la propia Inspección, "únicamente allí donde se quiere explotar el trabajo de las mujeres y niños, explotación que tiene como único y verdadero fundamento el consentimiento de los padres, la Inspección no es bien recibida" (p. 254). Dejando de lado el hecho que se ignora que los patronos también podían tener alguna responsabilidad en el trabajo infantil, de acuerdo con la misma ley por la que velaba la inspección, en el texto se vuelve a obviar que era la necesidad la causa del trabajo de los menores. Parece que el inspector imputa la responsabilidad únicamente a los padres, para así, tácitamente, exonerar al patrono.

El inspector regional se tropieza "con la dificultad de poder depurar la edad y circunstancias de los menores, a causa de la falta de los certificados que establece la ley, en razón a que los obreros no pueden proveerse gratuitamente de aquellos documentos" (p. 256).

En la $8^{\text {a }}$ región (Zaragoza, Huesca, Teruel, Navarra, Soria) la inspección encontró "una absoluta ignorancia de los preceptos legales" (p. 280), por lo que no es de extrañar que

intermedias de la producción se realizaran por trabajadores a domicilio, que empleaban sus propias herramientas y recibían una remuneración a destajo. También explica que 'la trenza de yute o cáñamo con la que se elaboraban las suelas se realizaba tradicionalmente a mano, por mujeres (las 'sogueras')'. 


\section{IUSLabor 3/2018}

se cite que la Ley de 1900 "no se cumple apenas en las provincias de esta región; pero donde más llama la atención del incumplimiento es en Mora de Rubielos, Rubielos de Mora, Nogueruelas y Beceite, localidades todas de la provincia de Teruel”, en las que "se hace trabajar a las mujeres y niños jornadas que en algunas ocasiones llegan a ser de 16 horas, sin conceder apenas descanso de ninguna clase; el trabajo de estas mujeres es, la mayor parte de las veces, a destajo, en locales insalubres, y los niños menores de 14 años se encuentran al frente de máquinas [...] en la última de dichas localidades se emplean también los menores de 16 años en operaciones extraordinariamente insalubres, como son la remoción de montones de trapos viejos" que eleva la temperatura y obliga a los niños a trabajar sin ropa (págs. 290-291). El uso de trapos viejos está relacionado con la industria del papel y por el uso del agua del río Matarraña por su paso por Beceite, la cual llegó a ser un importante centro papelero ${ }^{51}$; así, el proceso de producción de papel a partir de trapos viejos suponía la fase de seleccionado de los trapos, de su fermentado en el "pudridero", el desfibrado, la dilución de la pasta obtenida, la formación manual de hojas, el prensado y el secado, etc. La existencia de menores de 16 años en el proceso productivo del papel mediante trapos viejos, de hecho, suponía un incumplimiento expreso del artículo 2 del Decreto de 25 de enero de 1908, que prohibía el trabajo de menores de esa edad y de mujeres menores de edad en los talleres de elección, separación y preparación de los trapos para la producción de papel.

En las demás provincias tampoco se cumplía la ley y se cita expresamente la fábrica de papel "La Papelera Española, en Villava (Navarra), donde, según noticias del inspector, han llegado a ocurrir accidentes mortales hasta en menores de 14 años, y donde se obliga a estos menores a trabajar jornadas excesivas de noche sin conceder los descansos reglamentarios" (p. 291).

La intervención del inspector también tuvo éxito en algunos espectáculos públicos, en los que se consiguió evitar el trabajo de menores de 16 años en trabajos de agilidad, equilibrio, fuerza o dislocación (p. 291).

En Baleares "la industria que en estas islas tiene verdadera importancia es la domiciliaria",52, entre las que destacaba "el calzado, los bordados, los bolsillos de hilo

\footnotetext{
${ }^{51}$ EZQUERRO ESTEBAN, A.; El estudio de las marcas de agua del papel como material para determinar la datación y procedencia de las fuentes histórico-musicales, y su grado de fiabilidad; Anuario Musical, $\mathrm{n}^{\circ}$ 55, 2000, pp. 30-31. LOZANo LóPEZ, J.C.; Las fábricas de papel de Beceite (Teruel); Artigrama, $\mathrm{n}^{\circ} 14$, 1999, pp. 109-133.

${ }^{52}$ Pons, J.; BiBILONI, A.; El mercat de treball a la industria del calçat a Mallorca (1900-1970). El cas de Lloseta; Estudis Baleàrics, $\mathrm{n}^{\circ}$ 76/77, febrero/setiembre 2004, p. 142. Al respecto véase también EsCARTín BISBAL, J.M ${ }^{\mathrm{a}}$; La ciutat amuntegada. Indústria del calçat, desenvolupament urbà $i$ condicions de vida en la Palma contemporània (1840-1940); Edicions Documenta Balear, Palma de Mallorca, 2001. Y sobre el
} 


\section{IUSLabor 3/2018}

de plata", haciendo constar que el principal problema del trabajo a domicilio "es el empleo de muchachos, no dependientes del patrono, sino de los mismos obreros", reconociendo que "el obrero, que considera abusiva la explotación patronal, no tiene reparo en explotar a su vez al pobre muchacho, exigiéndole un gran número excesivo de horas de trabajo, dándole a veces malos tratos e imposibilitando su instrucción elemental" (p. 303).

También se explica que las infracciones relativas a la limitación de 6 horas en industrias y 8 en comercio de los menores entre 10 y 14 años se daban en "talleres de modista, y son motivadas por prolongar la velada después de las 10 de la noche, abuso que suele cometerse en los cambios de estación, en vísperas de festividades notables, de modo que no son muy frecuentes, y casi pueden fijarse los días en que suelen ocurrir" (p. 316 y 319); aunque también cita las infracciones en las industrias de construcción de calzado y alfarerías (p. 317) y se justifica en que "como el trabajo de aquéllos (menores) es auxiliar o complementario del que éstos (adultos) realizan, la diferencia de tiempo de trabajo causaría un quebranto que sólo pudiera remediarse sustituyendo a los menores por otros obreros, cuando ellos abandonaran el trabajo, lo cual sería oneroso para los fabricantes" (p. 318).

Pero resulta muy interesante que la misma Memoria explique por qué era racional el incumplimiento de la ley: el hecho de prescindir de los menores de 14 años podría suponer "perjuicios muy superiores a los que la ley quiere evitar. En efecto: las familias se verían privadas del jornal del menor; éste, alejado del trabajo hasta los 16 años, es probable que adquiriera, para toda la vida, hábitos de vagancia; perdería la época mejor para realizar su aprendizaje, y al empezar el trabajo a los 16 años, tendría que adquirir esta enseñanza, no recibiendo, mientras tanto, la remuneración que le correspondería de haber ingresado en el taller en edad menor. Estas gravísimas consecuencias han detenido el empeño del inspector de procurar la reducción de jornada del menor, contentándose con la seguridad de que la labor a que se le destina es ligera, obligando, por lo tanto, a que su esfuerzo sea proporcionado a su edad" (p. 318). En conclusión: el propio inspector justificaba y admitía el incumplimiento de la ley.

También es curioso que, en relación a las horas de instrucción de los menores, muchos patronos se hallaban dispuestos a no negarse "a dejar al menor las horas que marca el artículo 8 de la ley", pero que manifestaban "que la instrucción de los menores debía correr a cargo de los padres". A ello argumenta el inspector de Baleares entendiendo que no sería fácil asegurar que el menor fuera a la escuela, sino que sería probable que

trabajo femenino, ESCARTín BISBAL, J.Mª ; El quefer ocult. El mercat de treball de la dona en la Mallorca contemporània (1870-1940); Edicions Documenta Balear, 2001. 


\section{IUSLabor 3/2018}

"la mayor parte del tiempo concedido sin trabajar lo emplearan (los menores) en juegos o en vagar por las calles. Resultado: que nada se conseguiría respecto a enseñanza, y que, imponiéndose a los fabricantes la jornada reducida para los menores, se acabaría en breve con la asistencia de estos a las fábricas" (p. 318-319). Las palabras denotan una clara desconfianza y un verdadero paternalismo hacia los menores obreros.

En las Islas Canarias se cuenta que las muchas Juntas Locales de Reformas Sociales constituidas sólo existían nominalmente y no facilitaron la información requerida por el inspector, dado el carácter agreste y montañoso del territorio y los escasos medios de comunicación (p. 331).

Se explica que el trabajo de las mujeres "está casi en su totalidad reducido a la manufactura del tabaco y a las faenas agrícolas", pero el número de trabajadores en el primer tipo de industria era muy escaso. El inspector no logró identificar ninguna infracción referente al trabajo infantil y la existencia de éste "muy reducido" (p. 346347).

A modo de resumen, la Memoria de 1908 (págs. 362 y ss) entendió que "la Ley de mujeres y niños es la que menos se cumple entre las tutelares del obrero, correspondiendo el mayor número de infracciones a no presentar ni certificado de vacunación, ni permiso paterno" y que "teniendo en cuenta el elevado número de centros inspeccionados, son, en realidad, pocos los menores de 10 años que trabajan".

De hecho, "entre 273.000 individuos (que constan en el cuadro $\mathrm{N}$ de infracciones) sólo se encuentran 126 niños menores de 10 años. Las industrias a que asisten mayor número de estos individuos son las forestales y agrícolas, las textiles y las del vestido". Además, respecto al trabajo de menores en general, "las infracciones advertidas han sido considerables, habiéndose corregido las más graves en el acto mismo de la visita inspectiva" (p. 403) y "donde el progreso se manifiesta palpablemente es en la reducción de los operarios menores de 10 años" (p. 404).

Como veremos en la última de las partes de este artículo dedicado a las estadísticas de las Memorias, se comenta que "se ha continuado en este año el sistema persuasivo y de consejo, como lo prueba el que, a pesar del gran número de infracciones advertidas, sólo se han levantado 54 actas, es decir, el 0"25 por ciento de las infracciones". Por tanto, el trabajo de los inspectores durante el 1908 fue esencialmente de "persuasión", sin imponer casi ninguna sanción. Así, ¿esta actuación "persuasiva” suponía algún tipo de prevención en el cumplimiento de la norma? Lo veremos en las próximas Memorias. 
Pero al respecto nos resulta ilustrativo que para la inspección "siguen en pie los abusos advertidos en el año" 1907 sobre la falta de cumplimiento de la Ley de 1900: es decir, su actuación durante el año anterior no sirvió para que durante el 1908 se cumpliera la ley. Además, señala como causas de ello la necesaria competencia de los talleres modestos frente al "enorme rendimiento de las máquinas modernas", que obligan al trabajo de mujeres y niños que permite "abaratar el producto a expensas de la energía fisiológica de la operaria y del niño" (p. 400). Y otra causa de la inobservancia de la Ley "el estado de miseria de muchas comarcas, que obliga a los cabezas de familia a someterse, aceptando exiguas retribuciones, y a buscar en el mezquino jornal de los niños un suplemento necesario para subvenir a las perentorias necesidades de la vida" (p. 400). De ello se patentiza que la inspección conocía perfectamente los motivos de incumplimiento: la competencia de los patronos y la necesidad de los obreros. Pero, de hecho, no alega vicio o defecto alguno de la norma, ni propone, de momento, su modificación.

Finalmente, advierte (p. 407) que separar a un menor de un taller cuando se incumple la ley provoca que se le impida "el aprendizaje, precisamente en la edad más propia para realizarlo, se priva de un pequeño ingreso a su familia, y se le arroja infaliblemente al vagar de las calles, puesto que, por haber rebasado la edad escolar (de 12 años), no puede seguir completando su instrucción. De esta manera, ni el individuo, ni la familia, ni la sociedad, obtienen provecho alguno de la rigorosa aplicación de la Ley".

Este es el relato que las Memorias de la inspección de trabajo de 1907 y 1908 realizaron sobre el cumplimiento de la Ley del trabajo de mujeres y niños de 1900. Debido a su extensión, en las partes siguientes de este artículo se expondrán las Memorias hasta la de 1913.

\section{Anexo: comparativa de los textos de la Ley de mujeres y niños de 1900 durante su tramitación parlamentaria}

Tal y como hemos expuesto en el cuerpo de este escrito, creemos que es de gran ayuda para la comprensión de la tramitación parlamentaria de la ley poder comparar los textos que se fueron presentando y discutiendo en las Cortes. A ello va dedicado este anexo, en el que los colores rojo y verde señalan las adiciones y supresiones que van sufriendo los diferentes textos. 
IUSLabor 3/2018 


\begin{tabular}{|c|c|c|c|}
\hline Artículo & Proyecto de Ley - Primer dictamen & Segundo dictamen & 3r Dictamen - Ley \\
\hline 1 & $\begin{array}{l}\text { Los niños de ambos sexos menores de } \\
10 \text { años no serán admitidos en ninguna } \\
\text { clase de trabajo en establecimientos } \\
\text { mercantiles, fábricas, fundiciones, } \\
\text { construcciones, talleres, minas y } \\
\text { buques, siéndoles tan solo permitidas } \\
\text { las ocupaciones que tengan por objeto } \\
\text { el aseo, la conservaci6n y el cuidado de } \\
\text { los locales donde se ejerza la industria } \\
\text { y el comercio. }\end{array}$ & $\begin{array}{l}\text { Los niños de ambos sexos menores de } \\
10 \text { años no serán admitidos en ninguna } \\
\text { clase de trabajo en establecimientos } \\
\text { mercantiles, fábricas, fundiciones, } \\
\text { construcciones, talleres, minas y } \\
\text { buques, siéndoles tan solo permitidas } \\
\text { las ocupaciones que tengan por objeto } \\
\text { el aseo, la conservación y el cuidado de } \\
\text { los locales donde se ejerza la industria } \\
\text { y el comercio. }\end{array}$ & $\begin{array}{l}\text { Los menores de ambos sexos que no } \\
\text { hayan cumplido diez años no serán } \\
\text { admitidos en ninguna clase de trabajo. }\end{array}$ \\
\hline 2 & $\begin{array}{l}\text { Serán admitidos al trabajo los niños de } \\
\text { ambos sexos mayores de } 10 \text { y menores } \\
\text { de } 14 \text { años, por tiempo que no excederá } \\
\text { diariamente de seis horas en los } \\
\text { establecimientos industriales y de ocho } \\
\text { en los de comercio, interrumpidas por } \\
\text { descansos quo no sean en su totalidad } \\
\text { menores de una hora. } \\
\text { Desde los } 14 \text { a } 16 \text { años podrán ser } \\
\text { empleados en el trabajo los jóvenes de } \\
\text { ambos sexos durante ocho horas en los } \\
\text { establecimientos industriales y diez en } \\
\text { los mercantiles, interrumpidas por } \\
\text { descansos no inferiores en su duración }\end{array}$ & $\begin{array}{l}\text { La duración del trabajo efectivo de las } \\
\text { mujeres y de los niños de ambos sexos, } \\
\text { mayores de } 13 \text { años, no podrá exceder } \\
\text { de once horas diarias o de sesenta y seis } \\
\text { semanales en los establecimientos } \\
\text { industriales o mercantiles. La jornada } \\
\text { de trabajo será interrumpida por } \\
\text { descansos de una duración total de dos } \\
\text { horas y media, cuando menos. } \\
\text { Las Juntas locales y provinciales } \\
\text { creadas por esta ley propondrán al } \\
\text { Gobierno los medios que estimen } \\
\text { conducentes para que en el plazo de dos } \\
\text { años, a contar de la promulgación de la }\end{array}$ & $\begin{array}{l}\text { Serán admitidos al trabajo los niños de } \\
\text { ambos sexos, mayores de } 10 \text { y menores } \\
\text { de } 14 \text { años, por tiempo que no excederá } \\
\text { diariamente de seis horas en los } \\
\text { establecimientos industriales, y de ocho } \\
\text { en los de comercio, interrumpidas por } \\
\text { descansos que no sean en su totalidad } \\
\text { menores de una hora. } \\
\text { Las Juntas locales y provinciales } \\
\text { creadas por esta ley propondrán al } \\
\text { Gobierno los medios que estimen } \\
\text { conducentes, para que en el plazo de } \\
\text { dos años, a contar de la promulgación } \\
\text { de la misma, quede reducida a once }\end{array}$ \\
\hline
\end{tabular}




\begin{tabular}{|c|c|c|c|}
\hline & total a hora y media. & $\begin{array}{l}\text { misma, quede reducida } \\
\text { a once horas la jornada actual, donde } \\
\text { esta } \\
\text { excediese de las once horas. }\end{array}$ & $\begin{array}{l}\text { horas la jornada actual donde ésta } \\
\text { excediese de las once horas respecto de } \\
\text { las personas objeto de esta ley. }\end{array}$ \\
\hline 3 & $\begin{array}{l}\text { Queda prohibido a los menores de } 14 \\
\text { años todo trabajo nocturno. }\end{array}$ & $\begin{array}{l}\text { Cuando por causa de averías, sequia o } \\
\text { riadas tengan que suspender o } \\
\text { disminuir el trabajo las fábricas } \\
\text { movidas por fuerza de agua, la Junta } \\
\text { local estará facultada para autorizar el } \\
\text { trabajo en horas extraordinarias hasta } \\
\text { compensar la pérdida sufrida en el } \\
\text { curso del año. } \\
\text { También podrá autorizarlo en las } \\
\text { fábricas movidas a vapor para } \\
\text { compensar paros forzosos que hubiesen } \\
\text { ocurrido, y por épocas que se } \\
\text { determinarán en los respectivos } \\
\text { reglamentos, en las industrias cuyos } \\
\text { productos tengan la venta limitada d } \\
\text { cortas temporadas estacionales. } \\
\text { La ampliación de horas que se conceda } \\
\text { no excederá en ningún caso de doce } \\
\text { semanales. }\end{array}$ & $\begin{array}{l}\text { Cuando por causa de averías, sequía o } \\
\text { riadas, tengan que suspender o } \\
\text { disminuir el trabajo las fábricas } \\
\text { movidas por fuerza de agua, la Junta } \\
\text { local buscará y propondrá la forma de } \\
\text { suplir en horas extraordinarias la } \\
\text { pérdida sufrida en el curso del año. } \\
\text { También lo hará cuando en las fábricas } \\
\text { movidas a vapor sea necesario } \\
\text { compensar paros forzosos y por épocas } \\
\text { que se determinarán en los respectivos } \\
\text { reglamentos, en las industrias cuyos } \\
\text { productos ténganla venta limitada a } \\
\text { cortas temporadas estacionales. } \\
\text { La ampliación de horas no excederá en } \\
\text { ningún caso de doce semanales. }\end{array}$ \\
\hline 4 & $\begin{array}{l}\text { Queda prohibido a los menores de } 16 \\
\text { años: }\end{array}$ & $\begin{array}{l}\text { Queda prohibido el trabajo nocturno a } \\
\text { los niños de ambos sexos menores de }\end{array}$ & $\begin{array}{l}\text { Queda prohibido el trabajo nocturno a } \\
\text { los }\end{array}$ \\
\hline
\end{tabular}




\begin{tabular}{|c|c|c|c|}
\hline & $\begin{array}{l}\text { 1. }{ }^{\circ} \text { Todo trabajo subterráneo. } \\
\text { 2. }{ }^{\circ} \text { En el establecimiento destinados a } \\
\text { la elaboración o manipulación de } \\
\text { materias inflamables o insalubres, o en } \\
\text { cualquiera otra clase de trabajos que } \\
\text { ofrezcan peligro para su vida o } \\
\text { moralidad. }\end{array}$ & $\begin{array}{l}14 \text { años. } \\
\text { Queda prohibido también a los mayores } \\
\text { de } 14 \text { y menores de } 18 \text { años, en las } \\
\text { industrias que determinen las Juntas } \\
\text { locales y provinciales. } \\
\text { Para los efectos de esta ley, se } \\
\text { entenderá por trabajo nocturno el que } \\
\text { tenga lager desde las siete de la tarde } \\
\text { hasta las cinco de la mañana, con } \\
\text { descansos, como mínimo, de hora y } \\
\text { media. }\end{array}$ & $\begin{array}{l}\text { niños de ambos sexos menores de } 14 \\
\text { años. } \\
\text { Queda prohibido también a los mayores } \\
\text { de } 14 \text { años y menores de } 18 \text { años, en las } \\
\text { industrias que determinen las Juntas } \\
\text { locales y provinciales. } \\
\text { Para los efectos de esta ley, se } \\
\text { entenderá por trabajo nocturno el que } \\
\text { tenga lugar desde las siete de la tarde, } \\
\text { hasta las cinco de la mañana, con } \\
\text { descansos, como mínimo de hora y } \\
\text { media. } \\
\text { El trabajo nocturno no podrá exceder } \\
\text { de cuarenta y ocho horas semanales. }\end{array}$ \\
\hline 5 & $\begin{array}{l}\text { Queda prohibido A los menores de } 16 \\
\text { años todo trabajo de agilidad, } \\
\text { equilibrio, fuerza o dislocación en } \\
\text { espectáculos públicos. Los directores } \\
\text { de compañías, padres o tutores de los } \\
\text { menores que contravengan este } \\
\text { artículo, serán penados conforme al } 1 .^{\circ} \\
\text { de la ley de la protecci6n de los niños } \\
\text { de } 1 .^{\circ} \text { de Julio de } 1873 \text {. La prohibición } \\
\text { contenida en el artículo } 2 .^{\circ} \text { de esta ley } \\
\text { para los menores de } 16 \text { años, es }\end{array}$ & $\begin{array}{l}\text { Queda prohibido a los menores de } 16 \\
\text { años: } \\
\text { 1. }{ }^{\circ} \text { Todo trabajo subterráneo. } \\
2^{\circ} \text { Todo trabajo en establecimientos } \\
\text { destinados a la elaboración o } \\
\text { manipulación de materias inflamables y } \\
\text { en aquellas industrias calificadas de } \\
\text { peligrosas o insalubres, cuyo cuadro } \\
\text { fijará, el Gobierno } \\
\text { en los reglamentos, después de oído el } \\
\text { parecer de las Juntas locales y }\end{array}$ & $\begin{array}{l}\text { Queda prohibido a los menores de } 16 \\
\text { años: } \\
\text { 1. }{ }^{\circ} \text { Todo trabajo subterráneo. } \\
2 .^{\circ} \text { Todo trabajo en establecimientos } \\
\text { destinados a la elaboración o } \\
\text { manipulación de materias inflamables y } \\
\text { en aquellas industrias calificadas de } \\
\text { peligrosas ó insalubres, cuyo cuadro } \\
\text { fijará el Gobierno en los reglamentos, } \\
\text { después de oído el parecer de las Juntas } \\
\text { locales y provinciales. }\end{array}$ \\
\hline
\end{tabular}




\begin{tabular}{|c|c|c|c|}
\hline & $\begin{array}{l}\text { aplicable a cualquier clase de trabajo, } \\
\text { aunque revista carácter literario o } \\
\text { artístico ejecutado en espectáculo } \\
\text { público. } \\
\text { Las prohibiciones a que se refiere el } \\
\text { presente artículo quedan sometidas a } \\
\text { disposiciones de la autoridad } \\
\text { gubernativa, quien, para su dispensa, } \\
\text { apreciará la relación entre los } \\
\text { inconvenientes físicos y morales del } \\
\text { trabajo y las condiciones del niño. }\end{array}$ & provinciales. & $\begin{array}{l}\text { 3. La limpieza de motores y piezas de } \\
\text { transmisión, mientras esté funcionando } \\
\text { la maquinaria. }\end{array}$ \\
\hline 6 & $\begin{array}{l}\text { Las mujeres mayores de } 16 \text { años no } \\
\text { podrán } \\
\text { ser sometidas a trabajos cuya duración } \\
\text { total diaria exceda de } 10 \text { horas y que no } \\
\text { se hallen interrumpidas por descansos } \\
\text { de menos de dos horas en su totalidad, } \\
\text { ni que tengan lugar de noche y en } \\
\text { domingo y días festivos, salvo las } \\
\text { excepciones contenidas en el artículo } \\
7 .^{\circ} \text { que sean perjudiciales al organismo } \\
\text { femenino. }\end{array}$ & $\begin{array}{l}\text { Se prohíbe ocupar a los niños menores } \\
\text { de } 16 \text { años y a las mujeres menores de } \\
\text { edad, en talleres en los cuales se } \\
\text { confeccionen escritos, anuncios, } \\
\text { grabados, pinturas, emblemas, } \\
\text { estampas y demás objetos que, sin estar } \\
\text { bajo la acción de las leyes penales, sean } \\
\text { de tal naturaleza que puedan herir su } \\
\text { moralidad. } \\
\text { Queda prohibido a los menores de } 16 \\
\text { años todo trabajo de agilidad, } \\
\text { equilibrio, fuerza o dislocación en } \\
\text { espectáculos públicos. Los directores } \\
\text { de compañías, padres o tutores de los }\end{array}$ & $\begin{array}{l}\text { Se prohíbe ocupar a los niños menores } \\
\text { de } \\
16 \text { años y a las mujeres menores de } \\
\text { edad, en talleres en los cuales se } \\
\text { confeccionen escritos, anuncios, } \\
\text { grabados, pinturas, emblemas, } \\
\text { estampas y demás objetos que, sin estar } \\
\text { bajo la acción de las leyes penales, } \\
\text { sean de tal naturaleza que puedan herir } \\
\text { su moralidad. } \\
\text { Queda prohibido a los menores de } 16 \\
\text { años todo trabajo de agilidad, } \\
\text { equilibrio, fuerza o dislocación en } \\
\text { espectáculos públicos. Los directores }\end{array}$ \\
\hline
\end{tabular}




\begin{tabular}{|c|c|c|c|}
\hline & & $\begin{array}{l}\text { menores que contravengan este } \\
\text { artículo, serán penados conforme al } 1^{\circ} \\
\text { de la ley de la protección de los niños } \\
\text { de } 1 .^{\circ} \text { de Julio de } 1873 \text {. } \\
\text { La prohibici6n contenida en el artículo } \\
2 .^{\circ} \text { de esta ley para los menores de } 16 \\
\text { años, es aplicable a cualquiera clase de } \\
\text { trabajo, aunque revista carácter literario } \\
\text { o artístico ejecutado en espectáculo } \\
\text { público. } \\
\text { Las prohibiciones a que se refiere el }_{\text {presente artículo quedan sometidas a }} \\
\text { disposiciones de la autoridad } \\
\text { gubernativa, quien para su dispensa } \\
\text { apreciará la relación entre los } \\
\text { inconvenientes físicos y morales } \\
\text { del trabajo y las condiciones del niño. }\end{array}$ & $\begin{array}{l}\text { de compañías, padres o tutores de los } \\
\text { menores que contravengan este } \\
\text { artículo, serán penados conforme al } 1^{\circ} \\
\text { de la ley de la protección de los niños } \\
\text { de } 26 \text { de Julio de } 1878^{53} \text {. } \\
\text { La prohibición contenida en el párrafo } \\
\text { segundo de este artículo para los } \\
\text { menores de } 16 \text { años, es aplicable a } \\
\text { cualquier clase de trabajo, aunque } \\
\text { revista carácter literario o artístico, } \\
\text { ejecutado en espectáculo público. } \\
\text { Las prohibiciones a que se refiere el } \\
\text { presente artículo quedan sometidas a } \\
\text { las disposiciones de la Autoridad } \\
\text { gubernativa, quien, para su dispensa, } \\
\text { apreciará la relación entre los } \\
\text { inconvenientes físicos y morales del } \\
\text { trabajo y las condiciones del niño. } \\
\text { Se prohíbe el trabajo en domingo y días } \\
\text { festivos a los obreros que son objeto de } \\
\text { esta ley. }\end{array}$ \\
\hline 7 & $\begin{array}{l}\text { Podrá autorizarse el trabajo nocturno de } \\
\text { los jóvenes y menores de } 23 \text { años y }\end{array}$ & $\begin{array}{l}\text { El Ministro de la Gobernación } \\
\text { nombrará Juntas provinciales y locales }\end{array}$ & $\begin{array}{l}\text { El Ministro de la Gobernación } \\
\text { nombrará Juntas provinciales y locales }\end{array}$ \\
\hline
\end{tabular}

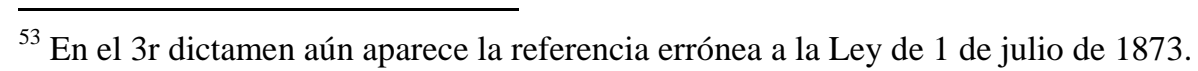




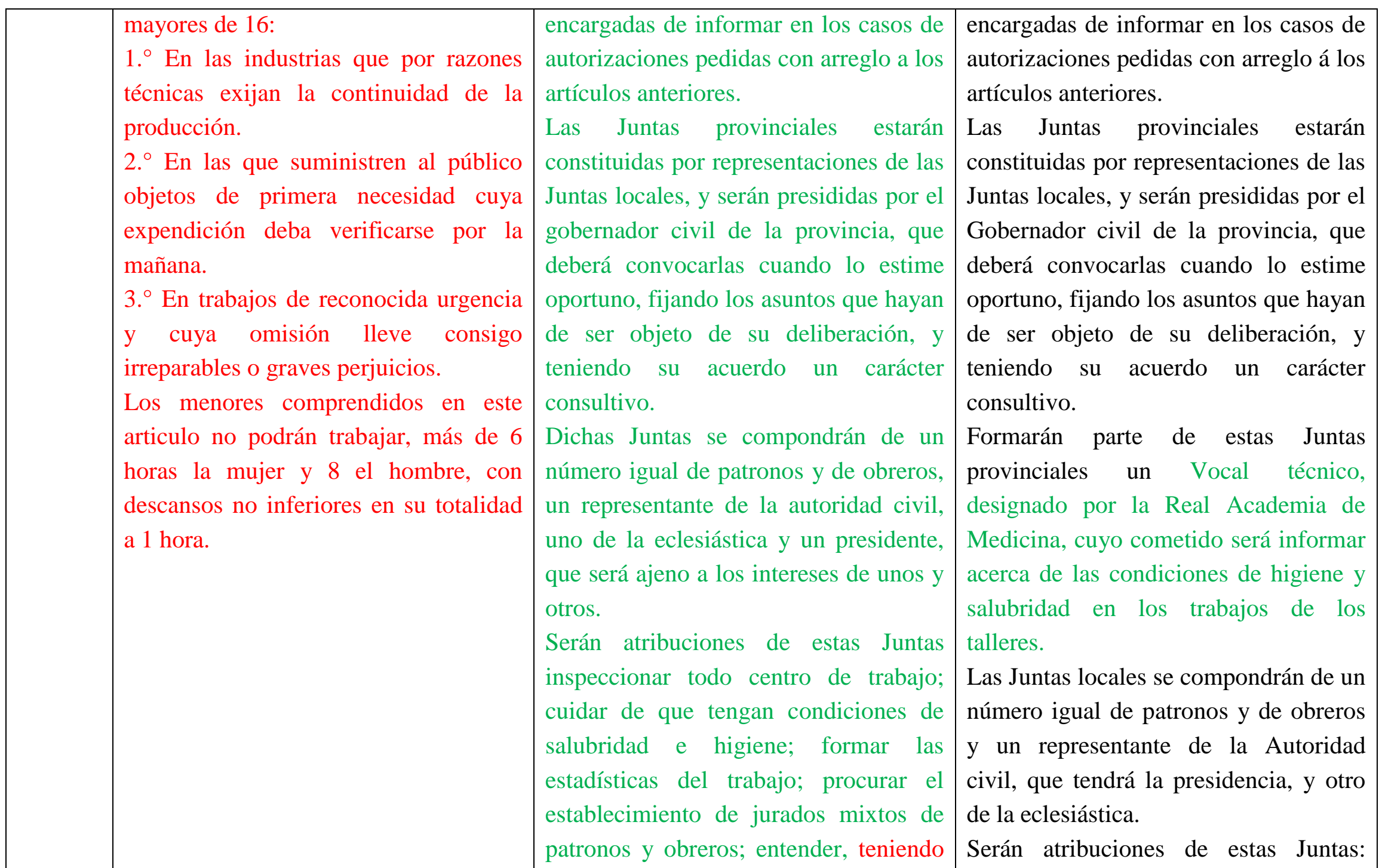




\begin{tabular}{|c|c|c|c|}
\hline & & $\begin{array}{l}\text { sus resoluciones carácter ejecutivo, en } \\
\text { las reclamaciones que unos y otros } \\
\text { sometieran a su deliberación, y velar } \\
\text { por el cumplimiento de esta ley, } \\
\text { singularmente donde se reúnan obreros } \\
\text { de ambos sexos, para quo se observe } \\
\text { una disciplina que evite todo quebranto } \\
\text { de la moral o de las buenas costumbres. }\end{array}$ & $\begin{array}{l}\text { inspeccionar todo centro de trabajo; } \\
\text { cuidar de que tengan condiciones de } \\
\text { salubridad é higiene; formar las } \\
\text { estadísticas del trabajo; procurar el } \\
\text { establecimiento de jurados mixtos de } \\
\text { patronos y de obreros; entender en las } \\
\text { reclamaciones que unos y otros } \\
\text { sometieran a su deliberación, y velar } \\
\text { por el cumplimiento de esta ley, } \\
\text { singularmente donde se reúnan obreros } \\
\text { de ambos sexos, para que se observe } \\
\text { una disciplina que evite todo quebranto } \\
\text { de la moral o de las buenas costumbres. } \\
\text { Esta organización será provisional } \\
\text { hasta la publicación de la ley de } \\
\text { Jurados mixtos. }\end{array}$ \\
\hline 8 & $\begin{array}{l}\text { La autorización a que se refiere el } \\
\text { artículo anterior se concederá por el } \\
\text { Gobierno, sus delegados o autoridades } \\
\text { a quienes competan estas funciones, } \\
\text { con arreglo a los reglamentos y } \\
\text { disposiciones complementarias que se } \\
\text { dicten para el cumplimiento de esta ley. }\end{array}$ & $\begin{array}{l}\text { Se concederán dos horas diarias por lo } \\
\text { menos, no computables entre las del } \\
\text { trabajo, para adquirir la instrucción } \\
\text { primaria y religiosa a los menores de } 14 \\
\text { años que no la hubiesen recibido, } \\
\text { siempre que haya escuela dentro de un } \\
\text { radio de dos kilómetros del } \\
\text { establecimiento en que trabajen. } \\
\text { Si la escuela estuviera a mayor }\end{array}$ & $\begin{array}{l}\text { Se concederán dos horas diarias, por lo } \\
\text { menos, no computables entre las del } \\
\text { trabajo, para adquirir la instrucción } \\
\text { primaria y religiosa á los menores de } 14 \\
\text { años que no la hubiesen recibido, } \\
\text { siempre que haya escuela dentro del } \\
\text { radio de dos kilómetros del } \\
\text { establecimiento en que trabajen. } \\
\text { Si la escuela estuviera á. mayor }\end{array}$ \\
\hline
\end{tabular}




\begin{tabular}{|c|c|c|c|}
\hline & & $\begin{array}{l}\text { distancia será, obligatorio sostener una } \\
\text { para el establecimiento fabril que ocupe } \\
\text { permanentemente en sus trabajos más } \\
\text { de } 20 \text { niños. } \\
\text { A los niños que acrediten saber leer y } \\
\text { escribir se les admitirá en la fábrica un } \\
\text { año antes de la edad marcada en la } \\
\text { presente ley. }\end{array}$ & $\begin{array}{l}\text { distancia, será obligatorio sostener una } \\
\text { para el establecimiento fabril que ocupe } \\
\text { permanentemente en sus trabajos más } \\
\text { de } 20 \text { niños. } \\
\text { A los niños que acrediten saber leer y } \\
\text { escribir se les admitirá en la fábrica un } \\
\text { año antes de la edad m arcada en la } \\
\text { presente ley. }\end{array}$ \\
\hline 9 & $\begin{array}{l}\text { Se concederán dos horas diarias por lo } \\
\text { menos, no computables entre las del } \\
\text { trabajo para adquirir la instrucción } \\
\text { primaria y religiosa a los menores de } 14 \\
\text { años que no la hubiesen recibido, } \\
\text { siempre que haya escuela dentro de un } \\
\text { radio de } 2 \text { kilómetros del } \\
\text { establecimiento en que trabajen. } \\
\mathrm{Si} \text { la escuela estuviere a mayor } \\
\text { distancia, será obligatorio sostener una } \\
\text { para el establecimiento fabril que ocupe } \\
\text { permanentemente en sus trabajos más } \\
\text { de } 20 \text { niños. }\end{array}$ & $\begin{array}{l}\text { No se permitir el trabajo a las mujeres } \\
\text { durante las tres semanas posteriores al } \\
\text { alumbramiento. } \\
\text { Cuando se solicite por causa de } \\
\text { próximo alumbramiento por una obrera } \\
\text { el cese, se la reservará el puesto desde } \\
\text { que lo haya solicitado, y tres semanas } \\
\text { después de dicho alumbramiento. }\end{array}$ & $\begin{array}{l}\text { No se permitirá el trabajo a las mujeres } \\
\text { durante las tres semanas posteriores al } \\
\text { alumbramiento. } \\
\text { Cuando se solicite por causa de } \\
\text { próximo alumbramiento por una obrera } \\
\text { el cese, se la reservará el puesto desde } \\
\text { que lo haya solicitado, y tres semanas } \\
\text { después de dicho alumbramiento. } \\
\text { Las mujeres que tengan hijos, en el } \\
\text { período de la lactancia, tendrán una } \\
\text { hora al día, dentro de las del trabajo, } \\
\text { para dar el pecho a sus hijos. } \\
\text { Esta hora se dividirá en dos períodos de } \\
\text { treinta minutos, aprovechables, uno, en } \\
\text { el trabajo de la mañana, y otro, en el de } \\
\text { la tarde. } \\
\text { Estas medias horas serán aprovechadas }\end{array}$ \\
\hline
\end{tabular}




\begin{tabular}{|c|c|c|c|}
\hline & & & $\begin{array}{l}\text { por las madres, cuando lo juzguen } \\
\text { conveniente, sin más trámite que } \\
\text { participar al director de los trabajos, y } \\
\text { al entrar en ellos, la hora que hubieren } \\
\text { escogido. } \\
\text { No será en manera alguna descontable } \\
\text { para el efecto de cobro de jornales la } \\
\text { hora destinada a la lactancia. }\end{array}$ \\
\hline 10 & $\begin{array}{l}\text { No se permitirá el trabajo a las mujeres } \\
\text { durante las tres semanas posteriores al } \\
\text { alumbramiento. }\end{array}$ & $\begin{array}{l}\text { No podrán ser admitidos en los } \\
\text { establecimientos industriales } \\
\text { mercantiles los niños, jóvenes y } \\
\text { mujeres que no presenten certificación } \\
\text { de estar vacunados y de no padecer } \\
\text { ninguna enfermedad contagiosa. }\end{array}$ & $\begin{array}{l}\text { No podrán ser admitidos en los } \\
\text { establecimientos industriales } y \\
\text { mercantiles los niños, jóvenes y } \\
\text { mujeres que no presenten certificación } \\
\text { de estar vacunados } \\
\text { y de no padecer ninguna enfermedad } \\
\text { contagiosa. }\end{array}$ \\
\hline 11 & $\begin{array}{l}\text { No podrán ser admitidos en los } \\
\text { establecimientos industriales } \\
\text { mercantiles los niños, jóvenes o } \\
\text { mujeres, que no presenten certificación } \\
\text { de estar vacunados y de no padecer } \\
\text { ninguna enfermedad contagiosa. }\end{array}$ & $\begin{array}{l}\text { Cuando el alojamiento de los obreros } \\
\text { dependa de alguna manera de los } \\
\text { dueños o empresarios de los } \\
\text { establecimientos industriales } \\
\text { mercantiles, será absolutamente } \\
\text { obligatorio el mantener una separación } \\
\text { completa entre las personas de diferente } \\
\text { sexo que no pertenezcan a una misma } \\
\text { familia. }\end{array}$ & $\begin{array}{l}\text { Cuando el alojamiento de Jos obreros } \\
\text { dependa en alguna manera de los } \\
\text { dueños ó empresarios de los } \\
\text { establecimientos industriales ó } \\
\text { mercantiles, será absolutamente } \\
\text { obligatorio el mantener una separación } \\
\text { completa entre las personas de diferente } \\
\text { sexo que no pertenezcan á una misma } \\
\text { familia. }\end{array}$ \\
\hline 12 & Cuando el alojamiento de los obreros & El Gobierno, oyendo al Consejo de & El Gobierno, oyendo al Consejo de \\
\hline
\end{tabular}




\begin{tabular}{|c|c|c|c|}
\hline & $\begin{array}{l}\text { dependa en alguna manera de los } \\
\text { dueños o empresarios de los } \\
\text { establecimientos industriales } \quad \text { o } \\
\text { mercantiles, será absolutamente } \\
\text { obligatorio el mantener una separación } \\
\text { completa entre las personas de diferente } \\
\text { sexo que no pertenezcan d una misma } \\
\text { familia. }\end{array}$ & $\begin{array}{l}\text { Sanidad } \\
\text { y a las Juntas provinciales, y previa la } \\
\text { informaci6n que estime necesaria, } \\
\text { clasificará todas las industrias y } \\
\text { trabajos para acomodar a esta } \\
\text { clasificación los artículos } \\
\text { correspondientes de la presente ley. }\end{array}$ & $\begin{array}{l}\text { Sanidad } \\
\text { y a las Juntas provinciales, y previa la } \\
\text { información que estime necesaria, } \\
\text { clasificará todas las industrias y } \\
\text { trabajos para acomodar a esta } \\
\text { clasificación los artículos } \\
\text { correspondientes de la presente ley. }\end{array}$ \\
\hline 13 & $\begin{array}{l}\text { El Gobierno, oyendo al Consejo de } \\
\text { sanidad } \\
\text { y autoridades que estime conveniente, } \\
\text { clasificará todas las industrial y trabajos } \\
\text { para acomodar a esta clasificación los } \\
\text { artículos correspondientes de la } \\
\text { presente ley. }\end{array}$ & $\begin{array}{l}\text { Las infracciones de esta ley se } \\
\text { castigarán con multa de } 25 \text { A } 250 \\
\text { pesetas, exigibles solamente a los } \\
\text { patronos, salvo el caso de que resulte } \\
\text { manifiesta la irresponsabilidad de los } \\
\text { mismos. } \\
\text { Las autoridades municipales serán las } \\
\text { encargadas de la imposición y cobro de } \\
\text { las referidas multas, cuyo producto } \\
\text { ingresará en las cajas de las Juntas } \\
\text { locales para mejorar la educación del } \\
\text { obrero. }\end{array}$ & $\begin{array}{l}\text { Las infracciones de esta ley se } \\
\text { castigarán con multa de } 25 \text { á } 250 \\
\text { pesetas, exigibles solamente á los } \\
\text { patronos, salvo el caso de que resulte } \\
\text { manifiesta la irresponsabilidad de los } \\
\text { mismos. } \\
\text { Las autoridades municipales serán las } \\
\text { encargadas de la imposición y cobro de } \\
\text { las referidas multas, cuando lo } \\
\text { determinen las Juntas locales y } \\
\text { provinciales, y su producto ingresará en } \\
\text { las Cajas de las Juntas locales } \\
\text { para mejorar la educación del obrero. }\end{array}$ \\
\hline 14 & 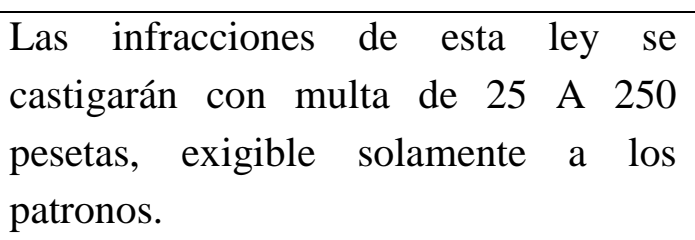 & $\begin{array}{l}\text { La inspección que exige el } \\
\text { cumplimiento de esta ley corresponderá } \\
\text { por su naturaleza al Gobierno, quien la } \\
\text { ejercerá asistido por representaciones }\end{array}$ & $\begin{array}{l}\text { La inspección que exige el } \\
\text { cumplimiento de esta ley corresponderá } \\
\text { al Gobierno, sin perjuicio de la misión } \\
\text { que en ella se confía á las Juntas locales }\end{array}$ \\
\hline
\end{tabular}




\begin{tabular}{|c|c|c|c|}
\hline & $\begin{array}{l}\text { En caso de reincidencia se impondrá en } \\
\text { su límite máximo. }\end{array}$ & $\begin{array}{l}\text { de las Juntas locales, provinciales y } \\
\text { curas párrocos. El gobernador civil será } \\
\text { el encargado de llevarla a cabo, } \\
\text { pudiendo en casos extraordinarios y } \\
\text { cuando la índole de los abusos lo } \\
\text { reclamaren, nombrarse delegados } \\
\text { especiales; pero siempre con facultades } \\
\text { concretas y por tiempo determinado, no } \\
\text { pudiendo en ningún caso crearse } \\
\text { delegados o inspectores permanentes. }\end{array}$ & y provinciales. \\
\hline 15 & $\begin{array}{l}\text { El Gobierno organizará los servicios de } \\
\text { inspección para el cumplimiento de esta } \\
\text { ley, y dictará en el término de seis } \\
\text { meses los reglamentos necesarios para } \\
\text { su ejecución. }\end{array}$ & $\begin{array}{l}\text { Si sobre la aplicación y ejecución de } \\
\text { esta ley se formalizara ante las } \\
\text { autoridades locales por su } \\
\text { representaci6n debidamente autorizada } \\
\text { de asociación legalmente constituida, } \\
\text { ya sea de obreros, de patronos y } \\
\text { obreros, o mixta de patronos y obreros, } \\
\text { instancia exponiendo los daños o } \\
\text { inconvenientes prácticos que se } \\
\text { originen en algún caso, el Gobierno, } \\
\text { oyendo a las Juntas locales y } \\
\text { provinciales respectivas, y previa toda } \\
\text { otra información que estimara } \\
\text { necesaria, podrá decretar la suspensión, } \\
\text { con las excepciones de aplicación de }\end{array}$ & $\begin{array}{l}\text { Si sobre la aplicación y ejecución de } \\
\text { esta ley se formalizará ante las } \\
\text { Autoridades locales, por la } \\
\text { representación debidamente autorizada } \\
\text { de Asociación legalmente constituida, } \\
\text { ya sea de obreros, de patronos ó mixta } \\
\text { de patronos y obreros, instancia } \\
\text { exponiendo los daños ó inconvenientes } \\
\text { prácticos que se originen en algún caso, } \\
\text { el Gobierno, oyendo á las Juntas locales } \\
\text { y provinciales respectivas, y en su caso } \\
\text { a la Comisión de Reformas Sociales, } \\
\text { podrá decretar la suspensión, con las } \\
\text { excepciones de aplicación de esta ley, } \\
\text { en la localidad de donde proceda la }\end{array}$ \\
\hline
\end{tabular}




\begin{tabular}{|c|c|c|c|}
\hline & & $\begin{array}{l}\text { esta ley, en la localidad de donde } \\
\text { proceda la reclamación y } \\
\text { exclusivamente para la industria o } \\
\text { trabajo a que la misma se refiera. }\end{array}$ & $\begin{array}{l}\text { reclamación, y exclusivamente para la } \\
\text { industria ó trabajo á que 1a misma se } \\
\text { refiere. }\end{array}$ \\
\hline 16 & $\begin{array}{l}\text { Si sobre la aplicación y ejecución de } \\
\text { esta ley se formalizara ante las } \\
\text { autoridades locales, por representación } \\
\text { debidamente autorizada de asociación } \\
\text { legalmente constituida, ya sea de } \\
\text { obreros o mixta de patronos y obreros, } \\
\text { instancia exponiendo los daños o } \\
\text { inconvenientes prácticos que se } \\
\text { originen en algún caso, el Gobierno, } \\
\text { oyendo a la Comisión de Reformas } \\
\text { Sociales, podrá decretar la suspensión } \\
\text { con las excepciones de aplicación de } \\
\text { esta ley en la localidad de donde } \\
\text { proceda la reclamación, y } \\
\text { exclusivamente para la industria o } \\
\text { trabajo a que ella se refiera. }\end{array}$ & $\begin{array}{l}\text { El Gobierno dictara, en el plazo de seis } \\
\text { meses, los reglamentos que exija la } \\
\text { ejecución de esta ley. }\end{array}$ & $\begin{array}{l}\text { El Gobierno dictará en el plazo de seis } \\
\text { meses los reglamentos que exija la } \\
\text { ejecución de esta ley. }\end{array}$ \\
\hline 17 & & $\begin{array}{l}\text { Los jefes de industrias están en la } \\
\text { obligación de fijar en lugar visible de } \\
\text { sus talleres las disposiciones de la } \\
\text { presente ley y los reglamentos } \\
\text { generales que para su ejecución se }\end{array}$ & $\begin{array}{l}\text { Los Jefes de industrias están en la } \\
\text { obligación de fijar en lugar visible de } \\
\text { sus talleres las disposiciones de la } \\
\text { presente ley y los reglamentos } \\
\text { generales que para su ejecución se }\end{array}$ \\
\hline
\end{tabular}




\begin{tabular}{|c|c|c|}
\hline & $\begin{array}{l}\text { vayan publicando, así como los } \\
\text { reglamentos particulares concernientes } \\
\text { a su industria y el de orden interior de } \\
\text { su establecimiento. } \\
\text { Se depositará una copia de este último } \\
\text { en la secretaria de la Junta local, en la } \\
\text { del Ayuntamiento respectivo, en la de } \\
\text { la Junta provincial y en el Gobierno } \\
\text { civil de la provincia. }\end{array}$ & $\begin{array}{l}\text { vayan publicando, así como los } \\
\text { reglamentos particulares concernientes } \\
\text { á su industria y el de orden interior de } \\
\text { su establecimiento. } \\
\text { Se depositará una copia de este último } \\
\text { en la Secretaría de la Junta local, en la } \\
\text { del Ayuntamiento respectivo, en la de } \\
\text { la Junta provincial y el Gobierno civil } \\
\text { de la provincia. }\end{array}$ \\
\hline 18 & & $\begin{array}{l}\text { Se declara pública la acción para } \\
\text { denunciar los hechos que infrinjan la } \\
\text { presente ley. }\end{array}$ \\
\hline
\end{tabular}




\section{Bibliografía}

BALCELLS, A.; Les dones treballadores a la fábrica i al taller domèstic de la Catalunya del segle XIX i primer terç del XX; Catalan Historical Review, nº 8, 2015.

BengoecheA, S.; Los empresarios catalanes ante los proyectos de ley regulando el trabajo de las mujeres (1855-1912); en BORDERÍAS, C. (editora); Género y políticas del trabajo en la España contemporánea. 1836-1936; Història del Treball, $\mathrm{n}^{\circ}$ 2, Icaria Editorial, Barcelona, 2007, págs. 97-126.

BORRÁS LLOP, J.M.; Actitudes patronales ante la regularización del trabajo infantil, en el tránsito del siglo XIX al XX. Salarios de subsistencia y economías domésticas; Hispania: revista española de historia; volumen 55, nº 190, 1995

BorRÁs LloP, J.M.; El trabajo infantil en la industria de Barcelona según el Censo Obrero de 1905; Historia Social, nº 33, 1999.

BORRÁS LlOP, J.M.; Los límites del primer intervencionismo estatal en el mercado laboral: las Juntas de Reformas Sociales, las Delegaciones del Consejo de Trabajo y el empleo de mujeres y niños (Cataluña, 1900-1930); en BORDERÍAS, C. (editora); Género y políticas del trabajo en la España contemporánea. 1836-1936; Història del Treball, $\mathrm{n}^{\circ}$ 2, Icaria Editorial, Barcelona, 2007, pp. 61 a 96.

Caballero Domínguez, M.; Marcos del Olmo, M.; García Encabo, C.; Las elites políticas en la provincia de Soria: los diputados a cortes en la restauración (18751923); Investigaciones históricas: Época moderna y contemporánea, 1995, N.15.

Calvo, À.; Estructura industrial $i$ sistema productiu a Catalunya durant la Primera Guerra Mundial; Recerques: historia, economía, cultura; nº 20, 1988.

CAMPS, E.; Trabajo infantil y estrategias familiares durante los primeros estadios de la industrialización catalana (1850-1925). Esbozos a partir del estudio de un caso; Cuadernos de Historia Contemporánea; volumen 24, 2002, pp. 263-279.

Deu i Baigual, E.; Els beneficis industrials durant la Primera Guerra Mundial: el cas de la industria llanera de Sabadell; Recerques: historia, economía, cultura; nº 20, 1988. 
ESCARTÍN BISBAL, J.Ma .; La ciutat amuntegada. Indústria del calçat, desenvolupament urbà $i$ condicions de vida en la Palma contemporània (1840-1940); Edicions Documenta Balear, Palma de Mallorca, 2001.

ESCARTÍN BISBAL, J.Mª ; El quefer ocult. El mercat de treball de la dona en la Mallorca contemporània (1870-1940); Edicions Documenta Balear, 2001.

ESPUNY TOMÀs, M.J.; El tiempo del trabajo: la ordenación histórica de una conquista laboral; Anuario de Historia del Derecho Español; nº 67, 1997.

EsPunY TOMÁs, M.J.; Mendicidad infantil: la ley sobre mendicidad y vagancia de los menores de diez y seis años de 23 de julio de 1903; IusLabor 4/2005.

EsPUNY TOMÁs, M.J.; Los orígenes de la Inspección de Trabajo en España (19062006); IusLabor $1 / 2006$.

ESPUNY TOMÁs, M.J.; Una tarea preventiva y represiva: las primeras actuaciones; en EsPunY TOMÁs, M.J.; PAZ TORRES, O. (coordinadoras); Inspección de Trabajo. 19062006; Tirant lo Blanc, Valencia, 2008.

ESPUNY TOMÁs, M.J.; La primera legislación social protectora de la mujer: una perspectiva comparada; en RAMOS VÁZQUEZ, I. (coordinadora); Derecho y Trabajo en el Siglo XIX; Dykinson, Madrid.

EZQUERRO EsteBAn, A.; El estudio de las marcas de agua del papel como material para determinar la datación y procedencia de las fuentes histórico-musicales, y su grado de fiabilidad; Anuario Musical, nº 55, 2000.

Gabriel, P.; Sous i cost de la vida a Catalunya a l'entorn dels anys de la Primera Guerra Mundial; Recerques: historia, economía, cultura; nº 20, 1988.

IBARZ, J.; Con gesto viril. Política sindical y trabajo femenino en la industria del vidrio en Barcelona, 1884-1930; en BoRDERÍAS, C.; Género y políticas del trabajo en la España contemporánea: 1836-1936; Icaria, Barcelona, 2007, pp. 191-225.

LowE, B.E.; The international protection of labor. Internacional labor organization, history and law; The Macmillan Company, New York, 1935. 
LOZANO LóPEZ, J.C.; Las fábricas de papel de Beceite (Teruel); Artigrama, nº 14, 1999, pp. 109-133.

LlADÓ Y VALLÉS, J.; Información abierta por el "Fomento del Trabajo Nacional" de Barcelona sobre el proyecto de ley regulando el trabajo de las mujeres y de los niños. Informe de Don Juan Lladó y Vallés. Abogado. Representante de la "Asociación Democrática” de Madrid; Tipografía Española, Barcelona, 1900.

MARTínez DomíngUeZ, B.; La formación del capital humano en Galicia (1860-1900): alfabetización y atraso económico; Revista Galega de Economía, volumen 12, número $1,2003$.

MIRANDA ENCARNACIÓN, J.A.; De la tradición artesana a la especialización industrial. El calzado valenciano, 1850-1930; Revista de Historia Industrial, n 4, 1993.

MIRÁs, J.A.; El impacto de la Primera Guerra Mundial en la industria de A Coruña; Revista de Historia Industrial; $n^{\circ} 29$, año XIV, 2005, 3

MONTERO GARCÍA, F.; La polémica sobre el intervencionismo y la primera legislación obrera en España. 1890-1900. $2^{a}$ parte: el debate político-parlamentario; Revista de Trabajo, $n^{\circ}$ 61-62, 1981.

NASH, M.; Trabajadoras: un siglo de trabajo femenino en Cataluña, 1900-2000; Generalitat de Catalunya, Departament de Treball, Barcelona, 2010.

Pons, J.; BIBILONI, A.; El mercat de treball a la industria del calçat a Mallorca (19001970). El cas de Lloseta; Estudis Baleàrics, no 76/77, febrero/setiembre 2004.

RAMOs VÁZQUEZ, I.; Derecho internacional obrero. Origen y concepto; IusLabor $3 / 2017$

RiAl GARCÍA, S.M.; Trabajo femenino y economía de subsistencia: el ejemplo de la Galicia moderna; Manuscrits, nº 27, 2009. 